\title{
Comprehensive review on synthesis and adsorption behaviors of graphene-based materials
}

\author{
Seul-Yi Lee ${ }^{1}$ and Soo-Jin Park ${ }^{2, s}$ \\ ${ }^{1}$ Korea CCS R\&D Center, Korea Institute of Energy Research, 152 Gajeongro, Yuseoung-gu, Daejeon 305-343, South Korea \\ ${ }^{2}$ Department of Chemistry, Inha University, 100 Inharo, Nam-gu, Incheon 402-751, South Korea
}

\section{Article Info}

Received 3 January 2012

Accepted 21 March 2012

\section{*Corresponding Author}

E-mail: sjpark@inha.ac.kr

Tel: $+82-32-860-8438$

\section{Open Access}

DOI: http://dx.doi.org/ 10.5714/CL.2012.13.2.073

This is an Open Access article distributed under the terms of the Creative Commons Attribution Non-Commercial License (http://creativecommons.org/licenses/ by-nc/3.0/) which permits unrestricted non-commercial use, distribution, and reproduction in any medium, provided the original work is properly cited.

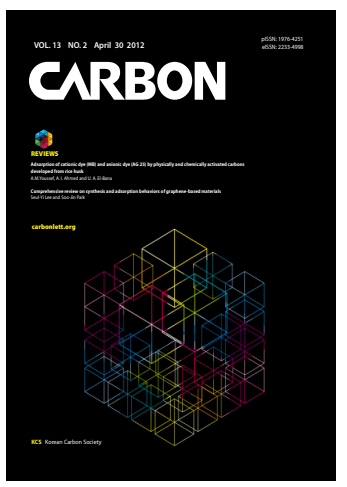

http://carbonlett.org

pISSN: 1976-4251

eISSN: 2233-4998

Copyright $\odot$ Korean Carbon Society

\begin{abstract}
Graphene is the thinnest known materials in the universe and the strongest ever measured. Graphene has emerged as an exotic material of the 21 st century and received world-wide attention due to its exceptional charge transport, thermal, optical, mechanical, and adsorptive properties. Recently, graphene and its derivatives are considered promising candidates as adsorbent for $\mathrm{H}_{2}$ storage, $\mathrm{CO}_{2}$ capture, etc. and as the sensors for detecting individual gas molecule. The main purpose of this review is to comprehensive the synthesis method of graphene and to brief the adsorption behaviors of graphene and its derivatives.
\end{abstract}

Key words: graphene, synthesis method of graphene, adsorption behaviors

\section{Introduction}

The discovery of graphene has been one of the most outstanding recent achievements $[1,2]$. Graphene is one of the most promising materials in nanotechnology because of its exceptional physical properties, such as high electronic conductivity, good thermal stability, and excellent mechanical strength. In particular, the promising properties together with the ease of processibility and functionalization make graphene-based materials ideal candidates for incorporation into various functional groups or materials.

As Fig. 1 demonstrates, the optimism about graphene is validated by the number of publications related to graphene, which dramatically increased after 2004 [3].

Importantly, graphene and its derivatives have been explored for a wide range of applications

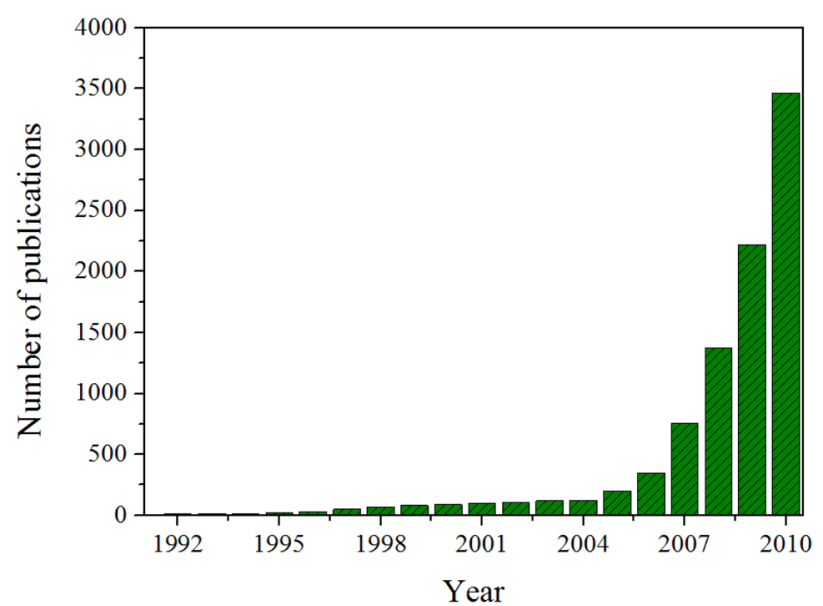

Fig. 1. Number of publication on graphene in the past 20 years (from ISI Web of Knowledge). 


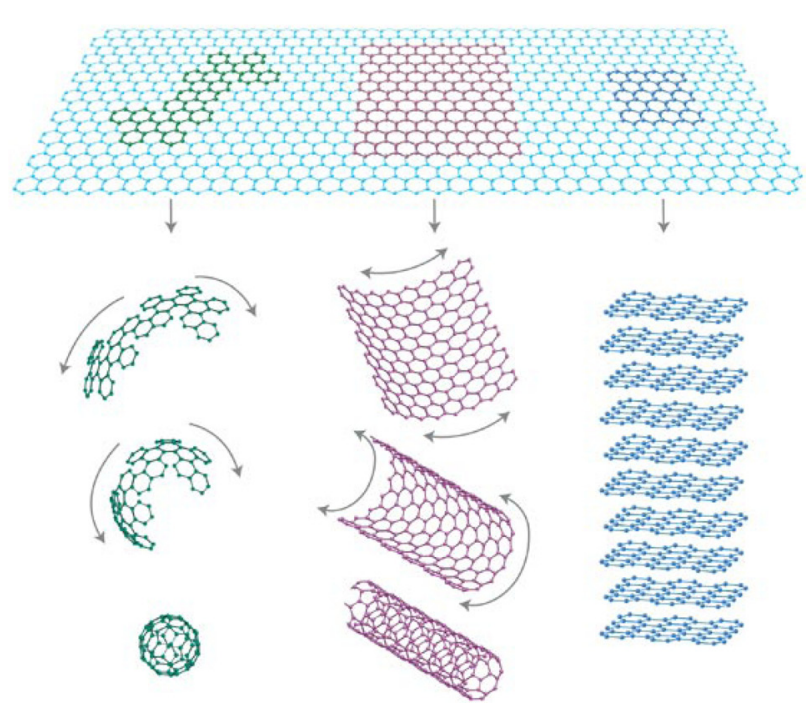

Fig. 2. Schematic representation of graphene: which is the fundamental starting material for a variety of fullerene materials, buckyballs, carbon nanotubes, and graphite [7].

in such fields as electronic and photonic devices, clean energy, and sensors [4-6]. Other forms of graphene-related materials, including graphene oxide, reduced graphene oxide, and exfoliated graphite, have been reliably produced on a large scale from the mother of all graphitic materials, as presented in Fig. 2 [7]. Graphene, one of the allotropes (such as carbon nanotubes, fullerene, diamond, and so on) of elemental carbon, is a planar monolayer of carbon atoms arranged in a two-dimensional (2D) honeycomb lattice with a C-C bond length of $0.142 \mathrm{~nm}$ [8]. Graphene is the thinnest of known materials in the universe and the strongest ever measured.

Its extended hexagonal monolayer network is the basic building block of other important allotropes, which can be stacked to form 3D graphite, rolled to form 1D nanotubes, and wrapped to form $0 \mathrm{D}$ fullerenes. As can be seen in Table 1, it has demonstrated a variety of intriguing properties, including high electron mobility at room temperature $\left(250000 \mathrm{~cm}^{2} /[\mathrm{V} \cdot \mathrm{s}]\right)$ [7], high specific surface area [8], superior mechanical properties with Young's modulus of $1 \mathrm{TPa}$ [10], and exceptional thermal conductivity $(5000 \mathrm{~W} /[\mathrm{m} \cdot \mathrm{K}])[11]$.

These potential characteristics are applied to single molecule gas detection, transparent conducting electrodes, composites, and energy storage devices, such as supercapacitors and lithium ion batteries [12-16]. Furthermore, a distinct band gap can be formed as the dimensions of graphene are reduced to narrow ribbons with a width of 1-2 nm, producing semi-conductive graphene with potential applications in transistors [17].

More recently, the adsorption behavior of graphene and graphene-based materials (its derivatives) has also been of interest due to graphene's high specific surface area and newly created textural properties.

After a general introduction to graphene and its derivatives, this review will demonstrate that graphene is not confined to only single-layer graphene nanosheets; it can have two-, three-, or multi-layer nanosheets. This will even include the graphenebased materials (its derivatives). Because adsorption behavior is mainly studied with graphene and its derivative-based materials, the purpose of this review is to look at, in a brief way, what is re-

\begin{tabular}{cccc}
$\begin{array}{l}\text { Table 1. Physical properties of single-layer graphene at room } \\
\text { temperature }\end{array}$ & Unit & Values & Ref. \\
\hline Content & $\mathrm{nm}$ & 0.142 & {$[8]$} \\
\hline $\begin{array}{c}\text { C-C bond length in } \\
\text { single-layer graphene }\end{array}$ & $\mathrm{m}^{2} / \mathrm{g}$ & $\sim 2630$ & {$[9]$} \\
\hline $\begin{array}{c}\text { Specific surface area } \\
\text { Electron mobility }\end{array}$ & $\mathrm{cm}^{2} /(\mathrm{V} \cdot \mathrm{s})$ & $\sim 2.5 \times 10^{5}$ & {$[7]$} \\
\hline at room temp.) & $\mathrm{TPa}$ & $\sim 1$ & {$[10]$} \\
\hline Young's modulus & $\mathrm{W} /(\mathrm{m} \cdot \mathrm{K})$ & $\sim 5.1 \times 10^{3}$ & {$[11]$} \\
\hline \begin{tabular}{c} 
Thermal conductivity \\
\hline
\end{tabular}
\end{tabular}

ferred to as graphene in the literature and the adsorption behavior of graphene and graphene-related materials for gas sensors, hydrogen storage, carbon dioxide capture, and so on.

\section{Synthesis of Graphene}

\subsection{Introduction}

Graphene with varying number of layers can be synthesized using different strategies, such as the growth of carbon nanotubes producing graphite with 100 layers of graphene, chemical vapor deposition in metal surfaces (a few layers of graphene), the thermal decomposition of $\mathrm{SiC}$, micromechanical exfoliation cleavage, chemical reduction of graphene oxide, and so on. Although, these various approaches did not produce perfect monolayer graphene, some studies showed that the chemical vapor deposition method has been optimized and become a major technique to produce graphene in large quantities [18]. Now, we briefly overview the various synthetic methods and the properties of the graphene produced by each synthetic method.

\subsection{Epitaxial growth and chemical vapor de- position technique}

For the development of large-scale synthesis of grown graphene, several methods have been studied by many researchers, including graphitization of $\mathrm{SiC}$ surfaces $[19,20]$ and chemical vapor deposition (CVD) on transition metals [21-24].

At first, epitaxial graphene research evolved out of work on carbon nanotubes. It is well known the carbon nanotubes have superior electronic properties. However, the inability to manufacture well-controlled tubes and scale them up from singletube transistors to large-scale integrated circuits has prevented expanded technological applications. It is presented in Fig. 3.

De Heer et al. $[25,26]$ realized that two-dimensional graphene, essentially unrolled nanotubes, would have many of the same properties as carbon nanotubes, and this idea opened the way to a new approach to carbon electronics. With an epitaxial method, ultrathin epitaxial graphite was grown on single-crystal silicon carbide by vacuum graphitization at high temperature. The material can be patterned using standard nanolithography methods [24-26].

Recently, Bae et al. [27] reported a roll-to-roll production of 30-inch graphene films using the CVD method. Their fabrica- 


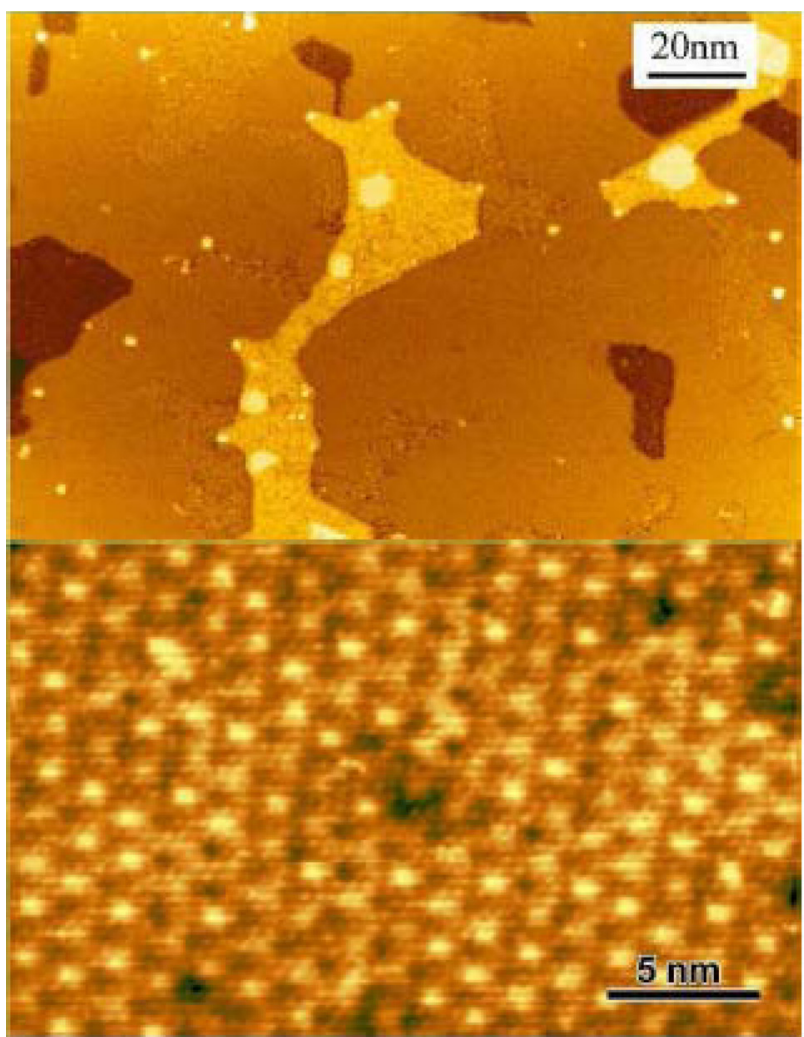

Fig. 3. Scanning tunneling microscope topographs $(0.8 \mathrm{~V}$ sample bias, $100 \mathrm{pA}$ ) of nominally $1 \mathrm{~mL}$ epitaxial graphene on $\mathrm{SiC}(0001)$. Top: image showing large flat regions of $6 \sqrt{3} \times 6 \sqrt{3}$ reconstruction and regions where the reconstruction has not fully formed. Next-layer islands are also seen. Bottom: a region of $6 \sqrt{3} \times 6 \sqrt{3}$ reconstruction, imaged through the overlying graphene layer (detailed information is presented in [19]).

tion process including three steps after the synthesis of graphene on copper substrates: (i) adhesion of polymer supports to the graphene on the copper foil; (ii) etching of the copper layers; and (iii) release of the graphene layers and transfer onto a target substrate (Fig. 4).

Epitaxially grown graphite has a number of differences related to physical properties in comparison with mechanically exfoliated graphene [28] due to the influence of interfacial effects in epitaxial graphene, which are strongly dependant on both the silicon carbide substrate and some growth parameters.

The second method involves substrate-based growth of single layers by a CVD technique. It has been reported that large and predominantly monolayer graphene of excellent quality can be synthesized by CVD on polycrystalline $\mathrm{Ni}, \mathrm{Cu}, \mathrm{Co}, \mathrm{Ru}$, and other transition metals $[29,30]$, with the flow of a hydrocarbon gas, such as methane, ethylene, acetylene, and benzene. In this procedure, the substrate is subjected to electron bombardment in an ultrahigh vacuum at $1000^{\circ} \mathrm{C}$ to remove oxide contaminants and then heated to temperatures ranging from $1250^{\circ} \mathrm{C}$ to $1450^{\circ} \mathrm{C}$ for a few minutes. Blakely et al. [31,32] reported the formation of carbon films by the cooling of $\mathrm{Ni}$ foils saturated with carbon at high temperatures.

This is known to be relatively simple and economical, and has been used to produce graphene that can reach impressive sizes and can be easily transferred to other substrates $[33,34]$.
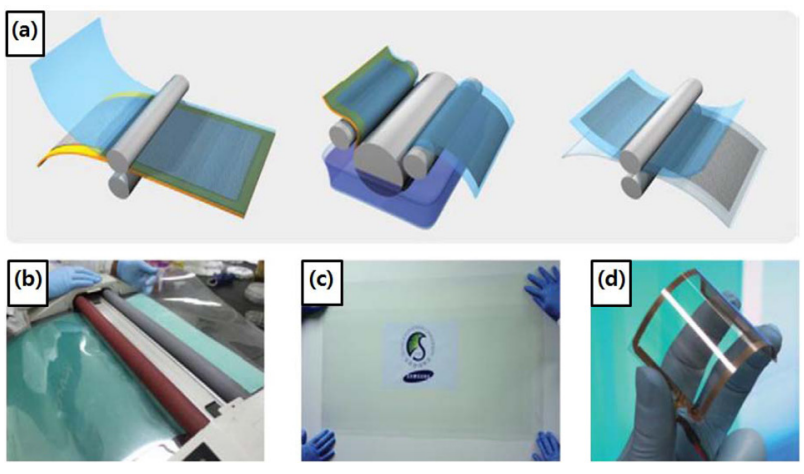

Fig. 4. (a) Schematic of the roll-based production of graphene films grown on a copper foil. The process includes adhesion of polymer supports, copper etching (rinsing) and dry transfer-printing on a target substrate. A wet-chemical doping can be carried out using a setup similar to that used for etching. (b) Roll-to-roll transfer of graphene films from a thermal release tape to a positron emission tomography (PET) film at $120^{\circ} \mathrm{C}$. (c) A transparent ultra large-area graphene film transferred on a 35-in. PET sheet. (d) An assembled graphene/PET touch panel showing outstanding flexibility [27].

Both epitaxial synthesis and CVD techniques take advantage of specially chosen platforms to encourage high-quality growth. They also have the prospect of producing a single sheet of graphene over an entire wafer.

Meanwhile, the following solution-based synthetic schemes by chemical reduction or exfoliation have no need for support substrates.

\subsection{Micromechanical exfoliation technique}

The micromechanical exfoliation technique is a simple peeling process. Fig. 5 show how a commercially available highly oriented pyrolytic graphite sheet was dry etched in oxygen plasma into many $5 \mu \mathrm{m}$ deep mesas.

Novoselov et al. [1] first observed single-layer graphene in 2004, as presented in Fig. 6. They isolated two-dimensional crystals from three-dimensional graphite using the mechanical exfoliation technique. As a result, single- and few-layer flakes are locked up substanding by only van der Waals forces and can be made free-standing by etching the substrate [35-38]. This attracted tremendous attention.

To exfoliate a single layer using mechanical exfoliation, the key is to overcome the van der Waals attraction $[39,40]$ between exactly the first and second layers without disarranging any subsequent layers. However, this method is a typical top-down approach of graphene, which requires manual effort and produces unreliable results, while small areas hinder practical applications of graphene [41,42].

Meanwhile, it is interesting note that mechanical exfoliation with cellophane tape from graphite is still considered best for producing the highest performing samples [39], among the various methods.

\subsection{Chemical reduction and thermal exfoliation}

In 1958, Hummers and Offeman [43] reported a method of preparing graphene oxide, which readily forms a stable colloidal 


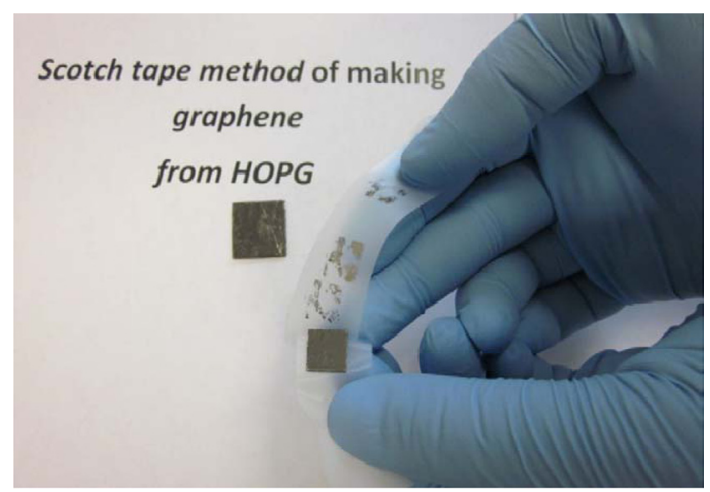

Fig. 5. Micromechanical exfoliation of graphene using scotch tape from highly oriented pyrolytic graphite.

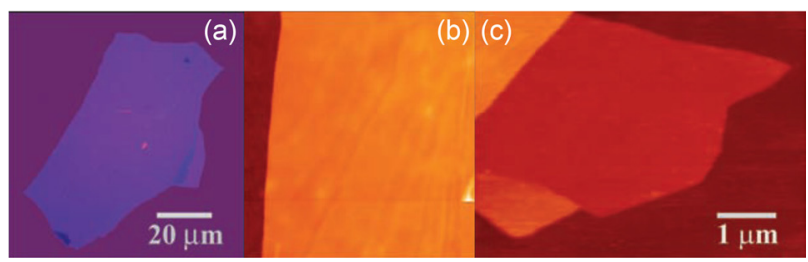

Fig. 6. Novoselov et al. [1] were the first to observe a single layer graphene; (a) photograph (in normal white light) of a relatively large multilayer graphene flake with a thickness of about $3 \mathrm{~nm}$ on top of an oxidized Si wafer, (b) atomic force microscope (AFM) image of $2 \mu \mathrm{m}$ by $2 \mu \mathrm{m}$ area of this flake near its edge (colors: dark brown, $\mathrm{SiO}_{2}$ surface; orange, $3 \mathrm{~nm}$ height above the $\mathrm{SiO}_{2}$ surface), (c) AFM image of single-layer graphene (colors: dark brown, $\mathrm{SiO}_{2}$ surface; brown-red (central area), $0.8 \mathrm{~nm}$ height; yellow-brown (bottom left), $1.2 \mathrm{~nm}$; orange (top left), $2.5 \mathrm{~nm}$. Notice the folded part of the film near the bottom, which exhibits a differential height of about $0.4 \mathrm{~nm}$ )

suspension in water. This graphene oxide suspension is used to facilitate production of single-layer graphene oxide by ultrasonic treatment (under the hundreds of $\mathrm{W}$ and tens of $\mathrm{kHz}$ ) [44-46].

By modifying the Hummers' methods, a tremendous number of studies on the synthetic method of graphene production have been published, and the produced graphene has been applied in a variety of applications. With improvement, gram quantities of graphene can also be obtained by a solvothermal procedure for preparing graphene oxide using sodium, potassium, ethanol, and so on $[47,48]$.

To synthesize graphene, the reduction of graphene oxide by chemical methods has been carried out using reducing agents, such as hydrazine [49-52], dimethylhydrazine [53], hydroquinone [54], and $\mathrm{NaBH}_{4}[55,56]$. A proposed reaction pathway for epoxide reduction with hydrazine is presented in Fig. 7.

The chemical reduction method by graphene oxide in solu-

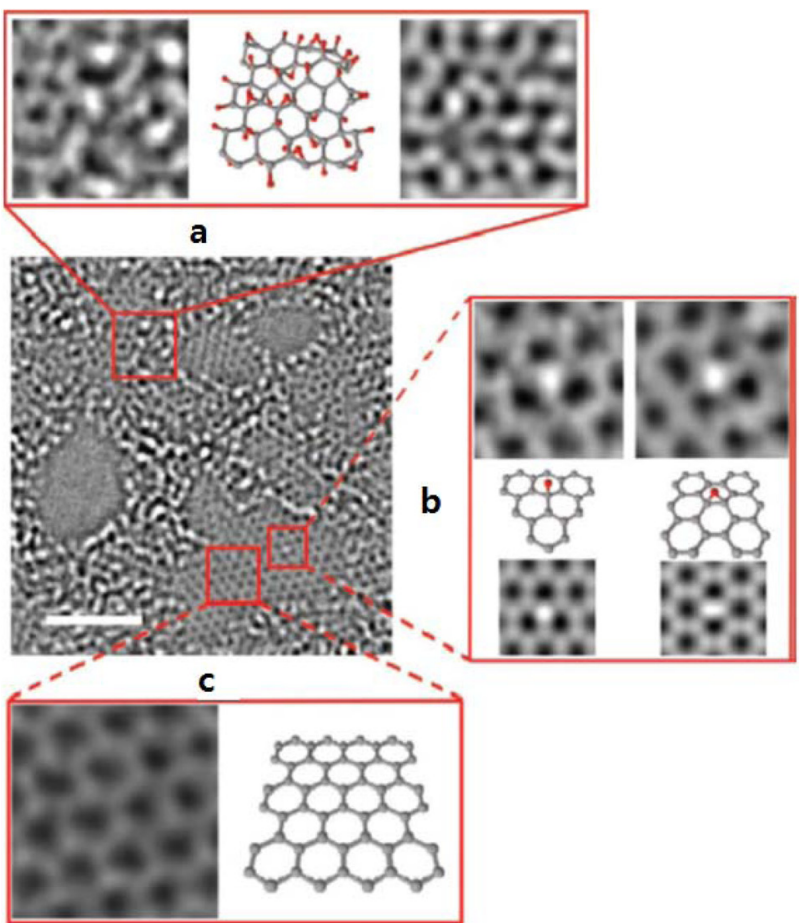

Fig. 8. Aberration-corrected transmission electron microscope image of a single sheet of suspended graphene oxide; (a) the oxidized region of the material, (b) the graphitic region, and (c) the atomic structure of graphite oxide's region [57].

tion allows easy manipulation and transfer of graphene onto substrates.

Erickson et al. [57] have investigated the local chemical structures on graphene oxide and reduced graphene oxide using the transmission electron microscopy (TEM) measurement (a monochromated aberration-corrected instrument operated at 80 $\mathrm{keV})$. The TEM image of graphene oxide clearly shows the oxidized area (Figs. 8a and b) and unoxidized graphene crystal area (Fig. 8c). As explained in the figure caption, hydroxyl groups and epoxy were presented on the graphene oxide basal plane. On the other hand, the TEM image of reduced graphene oxide shows the disordered regions (Fig. 8a) that is believed to result from the oxidized area being reduced by hydrazine and thermal annealing, and the unoxidized graphene regions.

An important method to synthesize graphene is thermal exfoliation of graphene oxide at high temperatures [58-60]. In this method, chemically prepared graphene oxide is placed in a well-sealed long-type quartz tube and then purged with inert gas. Then, the tube containing graphene oxide is quickly inserted into a muffle or tubular furnace preheated to $1050^{\circ} \mathrm{C}$ and<smiles>CCCCC(C)C(=O)C(C)NNN</smiles><smiles>CC1C(C)(C)C1(C)C</smiles>

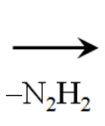<smiles>CC(C)=C(C)C</smiles>

$\mathrm{H}_{2} \mathrm{~N}$

Fig. 7. A proposed reaction pathway for epoxide reduction with hydrazine [49]. 


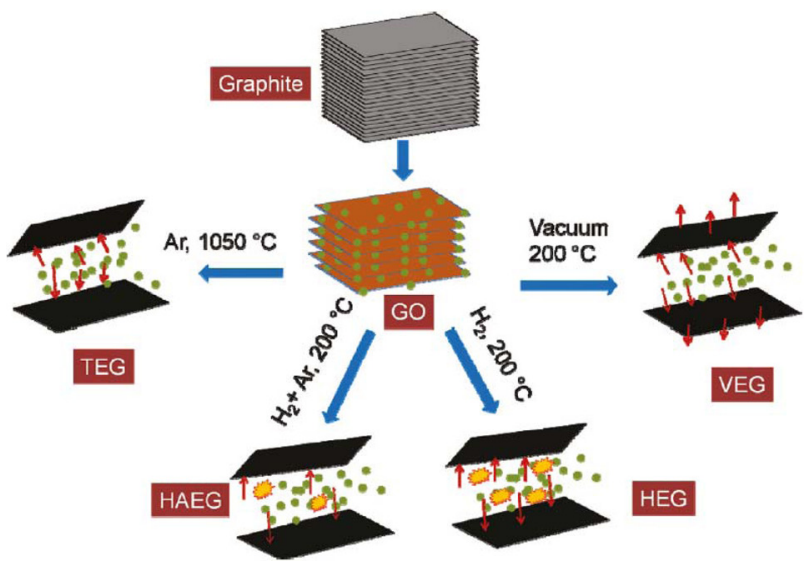

Fig. 9. Schematic representation of the mechanisms involved in "gasothermal" exfoliation techniques [60].

maintained at that temperature for around $10 \mathrm{~min}$. This is usually called exfoliated graphene.

Kaniyoor et al. [60] investigated that the effect of different exfoliation conditions on the synthesis of graphene from graphite oxide, for example, $\mathrm{Ar}$ at $1050^{\circ} \mathrm{C}$, vacuum at $200^{\circ} \mathrm{C}$, $\mathrm{H}_{2}+$ Ar mixture at $200^{\circ} \mathrm{C}$, and $\mathrm{H}_{2}$ at $200^{\circ} \mathrm{C}$. They found that these results showed conclusively that the atmosphere for exfoliation of graphite oxide plays a critical role in low temperature synthesis of graphene. It was observed that exfoliationreduction of graphite oxide in pure hydrogen atmosphere at $200^{\circ} \mathrm{C}$ results in the highest quality of a few layered graphene sheets. These schematic representation of the mechanisms are presented in Fig. 9.

\subsection{Others}

Few-layer graphene is synthesized by microwave treatment, conversion of nanodiamonds, and arc discharge of graphite. The method of preparing graphene by microwave treatment is just a post-process using chemically synthesized graphene oxide in large quantities in a short time [61-63]. Andersson et al. [64] and Prasad et al. [65] reported that graphene can be synthesized by heating nanodiamonds in an inert or reducing atmosphere. Nanodiamond particles are treated by soaking them in concentrated hydrochloric acid to avoid contamination by magnetic impurities. Then, they are annealed in a graphite container in a graphite furnace in a helium atmosphere at temperatures ranging from 1600 to $2500^{\circ} \mathrm{C}$.

Subrahmanyam et al. [66] reported that arc discharge of graphite in a hydrogen atmosphere yields graphenes exclusively containing 2 to 3 layers, although the flakes are relatively small (100 to $200 \mathrm{~nm}$ ). It has been found that this process depends on the presence of hydrogen gas during the arc discharge which terminates the dangling carbon bonds with hydrogen, which prevents the formation of closed structures [67]. To prepare graphene by the arc discharge method, direct current arc discharge of graphite evaporation is carried out in a water-cooled stainless steel chamber filled with a mixture of hydrogen and helium without any catalyst [68]. It has been reported that the best transition characteristics are exhibited by graphene synthesized by arc discharge of graphite in hydrogen.

\section{Adsorption Behaviors}

\subsection{Introduction}

The unique chemical properties of graphene affecting its adsorption behavior have only recently attracted the attention of many researchers; thus, it has not yet been studied in sufficient detail. Therefore, we will attempt to elucidate the adsorption behaviors of graphene and graphene-based materials.

Adsorption behavior depends significantly on the unique structure and concentration of chemical species created by a process of preparing graphene. It is possible to possess a large high surface area, sufficient porosity, superior conductivity, broad potential window, and rich surface chemistry. In addition, the extended polyaromatic $\pi$-electron system and coordinatively unsaturated terminal carbon atoms have a decisive effect on the reactivity of graphene. The readily polarizable $\pi$-electron system of graphene is equally reactive with electro- and nucleophilic species, and this makes the system sensitive even to radical species.

\subsection{Water physisorption}

A water cluster adsorbed on a graphite surface is a prototypical weakly bound van der Waals $\pi$-system that involves watergraphite and water-water interactions. Zhang and Sarkar [69] investigated that the binding energy of water clusters interacting with graphite is dependent on the number of water molecules that form hydrogen bonds, but is independent of the water cluster size, as presented in Fig. 10.

Furthermore, Lin et al. [70] found that these physically adsorbed or physisorbed water clusters show little change in their IR peak position and leave an almost perfect planar graphite surface. This is shown in Fig. 11.

\subsection{Hydrogen storage}

The US Department of Energy's revised gravimetric capacity target for hydrogen storage systems for 2015 is $5.5 \mathrm{wt} \%$. These targets have not yet been reproducibly met by any available storage technology. Solid carbon adsorbents, such activated carbons $[71,72]$, fullerenes [73,74], carbon nanotubes [75-78], graphites, carbon nanofibers [79-81], ordered porous carbon [82,83], and carbon-based hybrid composites [84,85], and so on, had previously been considered to be promising candidates for hydrogen storage due to their large surface area, structural stability, and light mass. In particular, the adsorption mode of $\mathrm{H}_{2}$ on carbon nanomaterials is reversible weak physisorption, which is a key factor in the operation of hydrogen/fuel-cell-powered systems.

To satisfy the increasing need for hydrogen storage, graphene has been attracting much attention as the newest carbon materials. It appears to be composed of a monolayer of carbon atoms packed into a dense honeycomb crystal structure. Single-layer graphene is theoretically predicted to have a large surface area of $2600 \mathrm{~m}^{2} / \mathrm{g}$, while the specific surface area of few-layer graphenes prepared by various methods is in the range from 250 to $1500 \mathrm{~m}^{2} / \mathrm{g}$.

Furthermore, recently, graphene-like nanosheets (in some cases, it has contained some oxygen functionalities; therefore, 


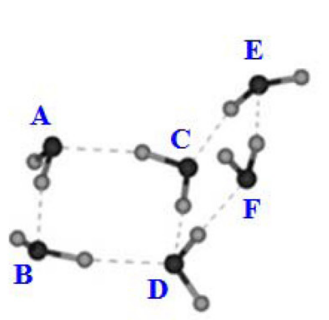

(a)

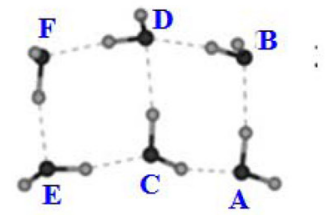

(d)

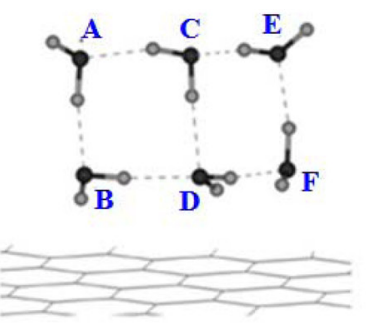

(b)

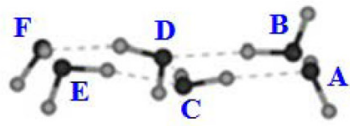

(f)

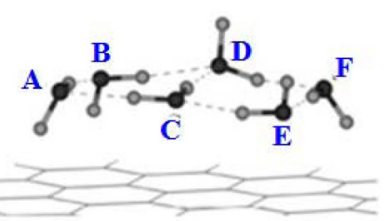

(c)

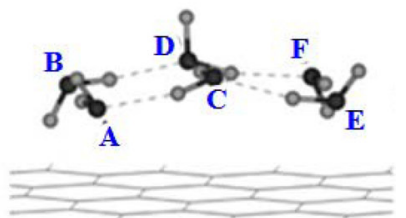

(g)

Fig. 10. Geometry structures of a booklike water hexamer (a) and that of different orientations (b, d) on the graphite surface, as well as the optimized adsorption structures (c, e, and f).

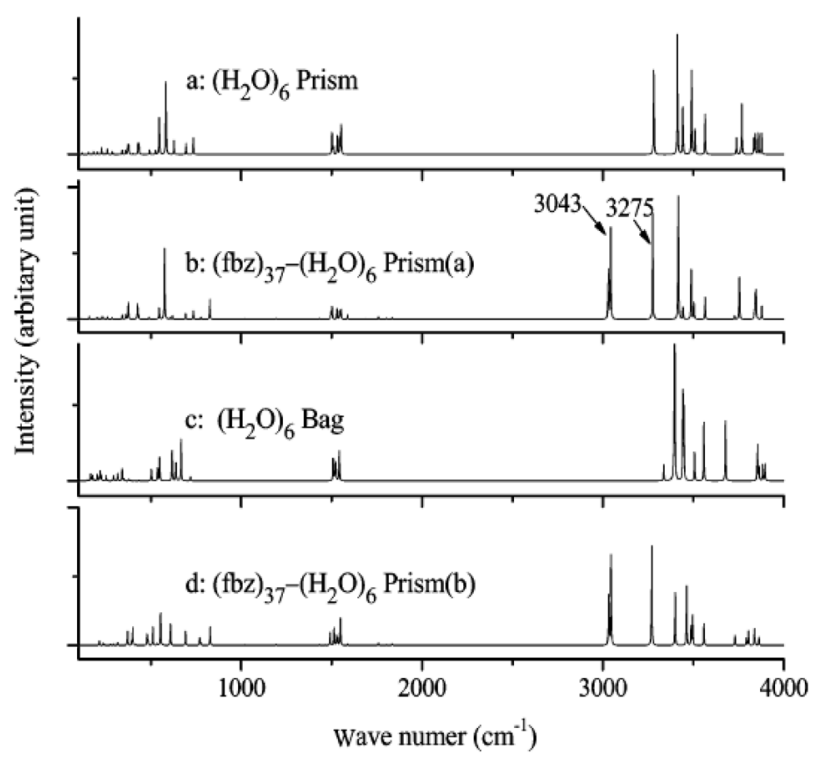

Fig. 11. Calculated infrared spectra of a free water hexamer and its adsorbed cases on a graphite surface: (a) prism $\left(\mathrm{H}_{2} \mathrm{O}\right)_{6}$, (b) (fbz) $)_{37}-\left(\mathrm{H}_{2} \mathrm{O}\right)_{6}$ prism $\mathrm{a}$, (c) bag $\left(\mathrm{H}_{2} \mathrm{O}\right)_{6}$, and (d) $(\mathrm{fbz})_{37}-\left(\mathrm{H}_{2} \mathrm{O}\right)_{6}$ prism b.

all of these graphene-like nano-materials are called "graphene oxide") have been studied in relation to the adsorption of hydrogen. They are produced relatively easily by oxidative treatment of graphitic materials with strong oxidizing agents. Graphene oxide is a stacked structure similar to graphite but with a wider spacing between graphene oxide nanosheet layers with diverse range of 6 to $15 \AA$ [86].

Srinivas et al. [87] studied graphene oxide prepared by the reduction of a colloidal suspension of exfoliated graphite oxide for hydrogen storage capacity. The nitrogen/77 K adsorptiondesorption isotherms and TEM/SEM images of synthesized

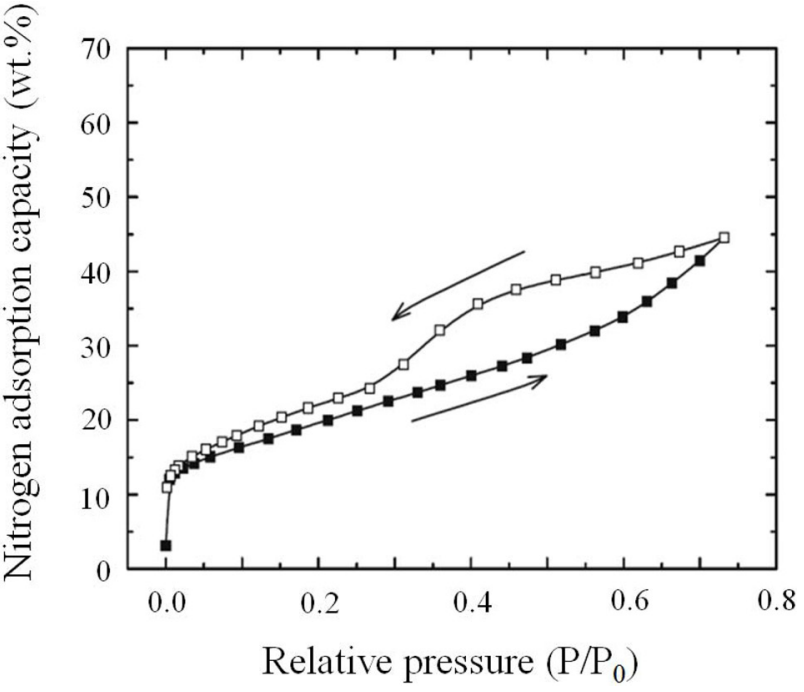

Fig. 12. Nitrogen/77 K adsorption-desorption isotherms of graphene oxide prepared from Srinivas et al. [87].

graphene oxide are presented in Figs. 12 and 13, respectively. As can be seen in Figs. 14 and 15, the sample was found to be in a highly agglomerated state with many wrinkles, and it had a specific surface area of $640 \mathrm{~m}^{2} / \mathrm{g}$ as measured by nitrogen adsorption at $77 \mathrm{~K}$.

The isotherms exhibited a typical type-I curve at low relative pressure and a hysteresis loop at relative pressure from 0.4 , indicating the presence of microporosity, mesoporosity, and some macroporosity [88]. They explained that the overlap and stacking of the exfoliated layers influenced the significant low textural characteristic.

In the Srinivas study, it was shown that the highest hydrogen storage capacities of a prepared sample were about $1.2 \mathrm{wt} \%$ and $0.1 \mathrm{wt} \%$ at pressures up to 10 bar under the temperatures 


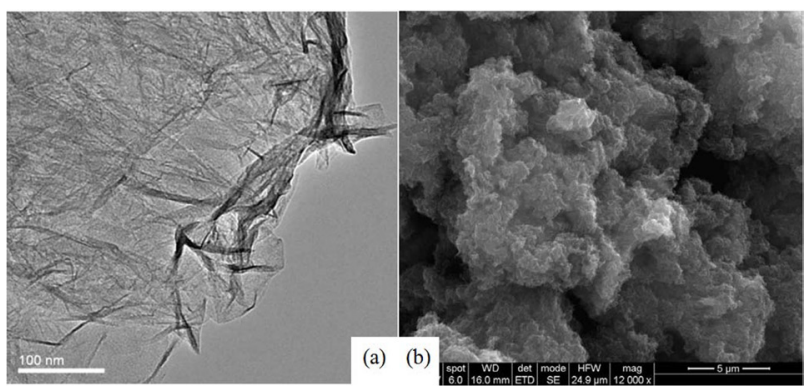

Fig. 13. Transmission electron microscope (a) and scanning electron microscope (b) images of graphene oxide prepared from Srinivas et al. [87].

of $77 \mathrm{~K}$ and $298 \mathrm{~K}$, respectively. Furthermore, they predicted the adsorption capacities at 100 bar of $\sim 3 \mathrm{wt} \%$ and $0.72 \mathrm{wt} \%$ at $77 \mathrm{~K}$ and $298 \mathrm{~K}$, respectively, obtained by linear extrapolation using the model LangmuirEXT2 expression. The room temperature hydrogen adsorption capacity was higher than other recent experimental results on hydrogen storage in a pristine graphene sample [89], which might be attributable to the higher isosteric heat of adsorption values. $\mathrm{Ma}$ et al. [89] reported that $0.4 \mathrm{wt} \%$ and $\sim 0.2 \mathrm{wt} \%$ hydrogen uptake of graphene oxide were obtained at $77 \mathrm{~K}$ under 1 bar and $298 \mathrm{~K}$ under 60 bar, respectively.

Ghosh et al. [90] found that high hydrogen adsorption capacity on graphene oxide obtained by thermal exfoliation or conversion of nanodiamond was $3.1 \mathrm{wt} \%$ (in case of single-layer graphene) at $298 \mathrm{~K}$ and 100 bar. As shown in Fig. 14, the hydrogen uptake varied linearly with the specific surface area, and the presence of more than one layer of graphene oxide in this study caused a decrease in the hydrogen uptake. In addition, the specific surface area of graphene oxide depends on the number of layers, not the pore effect [91,92].

It is interesting to note that the $\mathrm{H}_{2}$-graphene interaction energies obtained in their study satisfy the optimum conditions for adsorptive storage of hydrogen [93]. They also expected that higher values for hydrogen storage should be possible by preparing better samples and by reducing the average number of graphene layers.

The transition metal loaded/graphene oxide composites for hydrogen storage are being extensively researched. Wang et al. [94] have investigated the structural properties of graphene oxide and the feasibility of using graphene oxide to anchor Ti for hydrogen storage with first-principles computations. They reported that on graphene oxide there exist stable structural motifs as the basic function units of oxygen functionalities. It is consid-

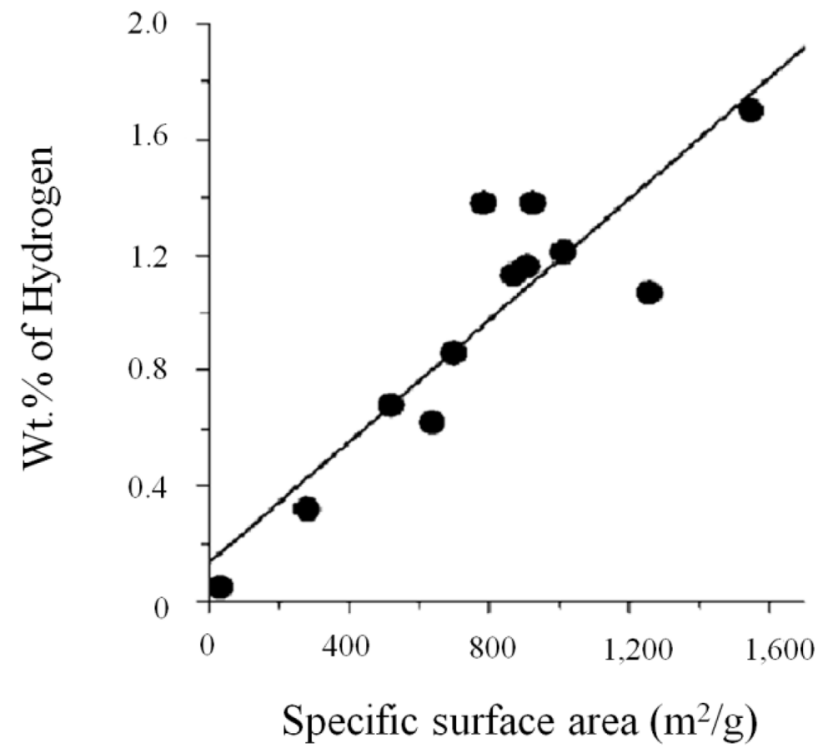

Fig. 14. Linear relationship between the specific surface area and the hydrogen storage capacity at $77 \mathrm{~K}$ and 1 bar.

ered that graphene oxide could be an excellent substrate for $\mathrm{Ti}$, but for hydrogen storage, it requires the hydrogenation of epoxy and open $\mathrm{sp}^{2}$ sites. Upon hydrogenated graphene oxide, the Ti binding energy is increased to a level that is high enough to prevent Ti clustering. Dihydrogen binding energy is also favorable for room temperature storage. The theoretical gravimetric density was $4.9 \mathrm{wt} \%$. Thus, Ti-anchored graphene oxide may offer a feasible solution for hydrogen storage.

Kim and Park [95] have reported nickel/graphite hybrid materials which are produced by mixed acid treatment of graphite flakes for hydrogen storage. The graphene oxide samples were prepared by dipping graphite flake into a mixed acid solution $\left(\mathrm{H}_{2} \mathrm{SO}_{4}\right.$ and $\left.\mathrm{H}_{2} \mathrm{O}_{2}\right)$ in a range of from 10:1 to 5:5 at room temperature. The experimental conditions of mixed acid treatments and textural properties of produced graphene oxides are listed in Table 2.

Fig. 16 is a schematic of the pore development of a graphite flake using the acidic method. The layer distance of each graphite sheet is nearly $0.354 \mathrm{~nm}$, and it is impossible for hydrogen molecules to be adsorbed at this dimension. However, after the expansion of the layers, the layer distance widens and new adsorption sites become exposed for hydrogen molecules.

Furthermore, Ni nanoparticles were loaded onto graphene ox-

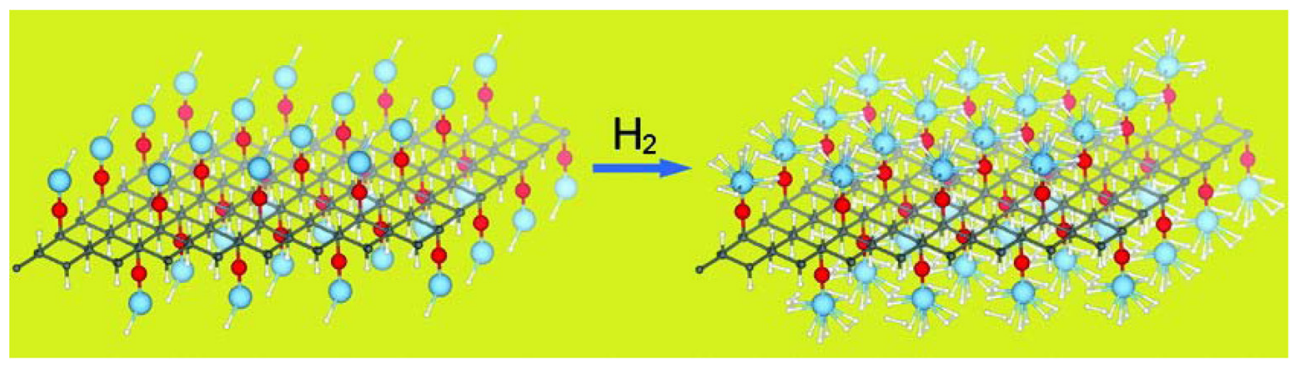

Fig. 15. The multi-binding hydrogen adsorption model of Ti-anchored graphene oxide [94]. 


\begin{tabular}{ccc}
\multicolumn{3}{c}{ Table 2. Specific surface area and pore volumes of graphene ox- } \\
ide as a function of the mixed acid ratio \\
$\begin{array}{c}\text { Mixed acid ratio } \\
\left(\mathrm{H}_{2} \mathrm{SO}_{4}: \mathrm{H}_{2} \mathrm{O}_{2}\right)\end{array}$ & $\begin{array}{c}\text { Specific surface area } \\
\left(\mathrm{m}^{2} / \mathrm{g}\right)\end{array}$ & $\begin{array}{c}\text { Total pore volume } \\
\left(\mathrm{cm}^{3} / \mathrm{g}\right)\end{array}$ \\
\hline As-received & $<5$ & - \\
\hline $10: 1$ & 145 & 0.056 \\
\hline $8: 2$ & 110 & 0.042 \\
\hline $6: 4$ & 80 & 0.031 \\
\hline $5: 5$ & 65 & 0.025 \\
\hline
\end{tabular}

(a)

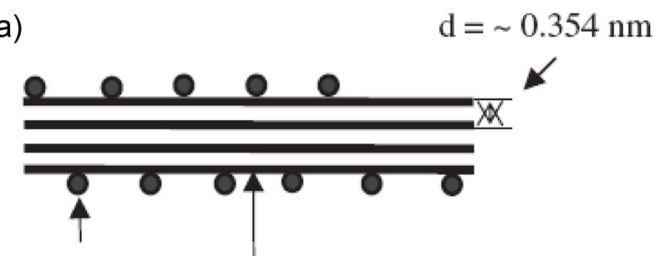

$\mathrm{H}_{2}$ molecule

Graphitic sheet

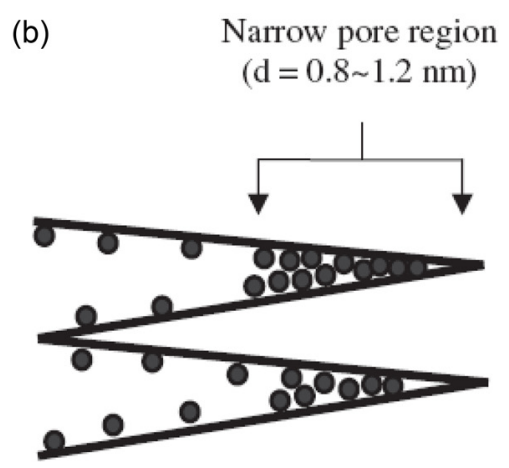

Fig. 16. A schematic of hydrogen storage sites on graphite surfaces: (a) as-received graphite and (b) graphene oxide manufactured by mixed acid treatments in this study.

ide surfaces as a function of $\mathrm{Ni}$ content in an effort to increase the final hydrogen uptake. In Fig. 17, the highest hydrogen storage result of the $8: 2 / \mathrm{Ni}-0.05$ sample was $4.48 \mathrm{wt} \%$, which was prepared by $0.05 \mathrm{wt} \%$ of $\mathrm{NiSO}_{4}$ per $1 \mathrm{~g}$ of graphene oxide.

However, it is important to note that the 10:1 sample showed lower hydrogen uptake the 8:2 sample, though the former had a higher specific surface area. This result indicates that the $8: 2$ samples may have a more suitable pore dimension for the adsorption of hydrogen molecules. Though the 10:1 sample had a high specific surface area, it was checked by a nitrogen molecule, indicating that the area was not suitable for hydrogen molecules.

Park et al. [95] suggested the newly a dipole-induced mechanism for hydrogen storage. As shown in Fig. 18, the first hydrogen molecules introduced can be reacted with metal particles due to the high oxidation power of metals on graphite surfaces due to the Kubas reaction [96,97].

Here, unlike the chemical binding of hydrogen atoms to transition metal on carbon surfaces, lone transition metal atoms bind hydrogen via the so-called "Kubas interaction," in which the

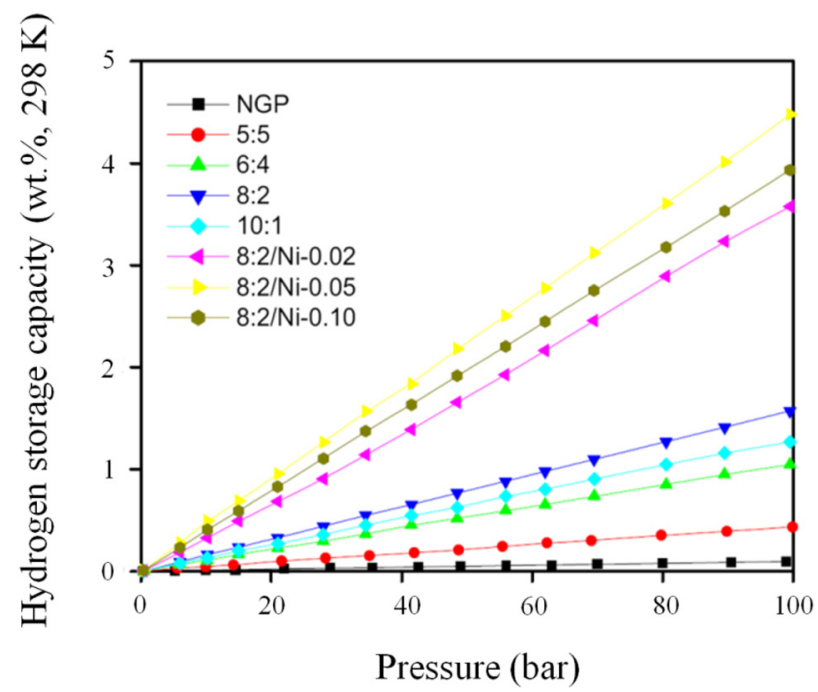

Fig. 17. Hydrogen storage behavior of graphene oxide as a function of mixed acid ratio and nickel content.
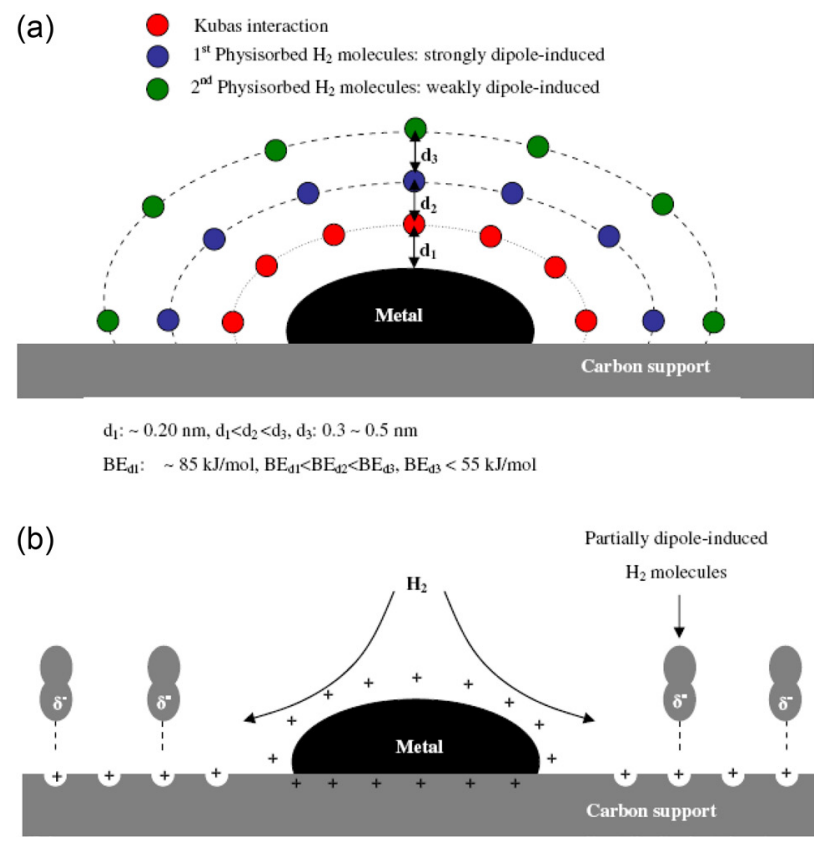

Fig. 18. A schematic of the hydrogen storage mechanism on metal/ carbon surfaces: (a) the accumulation of hydrogen molecules on metal/ carbon surfaces, (b) the dispersion of hydrogen molecules from metals to carbon surfaces by dipole-induced effects [95].

$\mathrm{H}-\mathrm{H}$ bond undergoes some elongation rather than complete dissociation into atoms.

However, the amount of this initial reaction is very small. The binding energy and bond distance in this case are $85 \mathrm{~kJ} / \mathrm{mol}$ and $0.2 \mathrm{~nm}$, respectively, because the binding energy and bond distance of metal hydride are normally close to $85 \mathrm{~kJ} / \mathrm{mol}$ and 0.2 $\mathrm{nm}$, respectively. The second group of hydrogen molecules introduced cannot chemically react due to a site limitation caused by the initially introduced hydrogen molecules; however, they are physically adsorbed by dipole-induced effects. The hydro- 


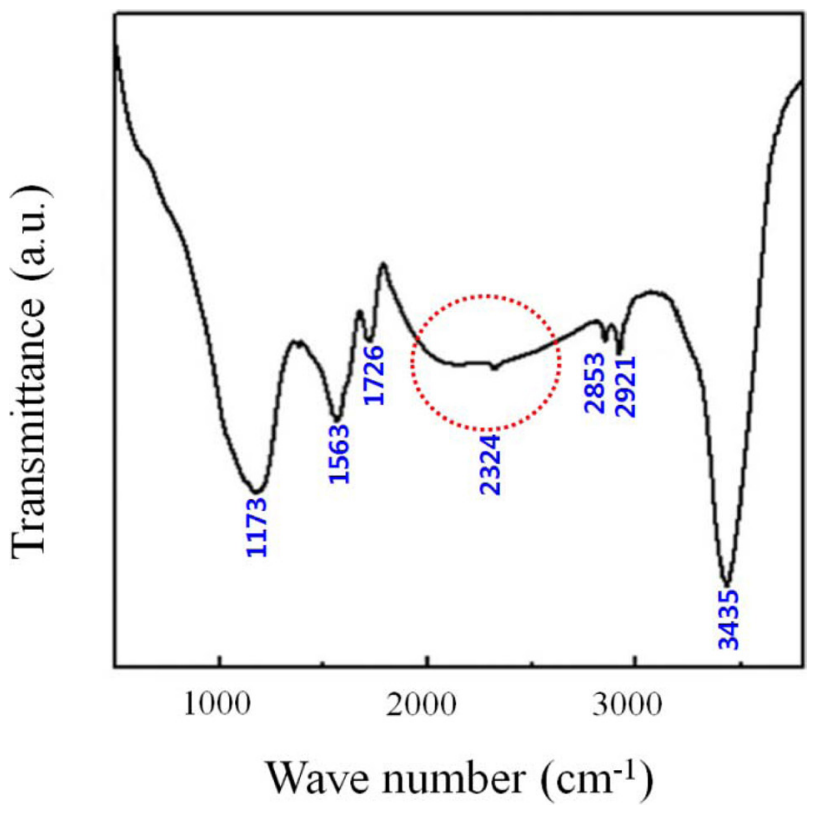

Fig. 19. Fourier transform infrared spectrum of molecular adsorption of $\mathrm{CO}_{2}$ in graphene oxide sample.

gen molecules are basically non-polar, but the strong interaction of the metal particles leads to the dipole inducing effects of the hydrogen molecules. The third group and any remaining hydrogen molecules are adsorbed by the same mechanism of high gas pressure, but this equilibrium can be broken when the interaction of oxidized graphite surfaces and dipole-induced hydrogen molecules is stronger than metal-hydrogen interactions [98-102]. This mechanism can be applied only under higher pressure, and when graphite supports are charged strong electron acceptors.

These unique characteristics of graphene oxide can play a leading part in enhancing hydrogen storage capacity.

\subsection{Carbon dioxide capture}

Mishra and Ramaprabhu [103] suggested graphene oxide for $\mathrm{CO}_{2}$ adsorption, which is prepared by hydrogen-induced thermal exfoliation of graphene oxide at $200^{\circ} \mathrm{C}$ for possible large-scale production of graphene [104]. They confirmed the physical adsorption of $\mathrm{CO}_{2}$ in graphene oxide using Fourier transform infrared spectroscopy.

In Fig. 19, the band corresponding to - $\mathrm{OH}$ groups at 3435 $\mathrm{cm}^{-1}$ is quite prominent compared by the insignificant ratios of anti-symmetric and symmetric $=\mathrm{CH}_{2}$ vibrations for graphene oxide in this work. Furthermore, the intense peaks correspond to the carboxylic and carbonyl groups at $1726(>\mathrm{C}=\mathrm{C}), 1563$ $(=\mathrm{CH}-)$, and $1173 \mathrm{~cm}^{-1}(>\mathrm{C}=\mathrm{O})$. An additional peak of $2324 \mathrm{~cm}^{-1}$ corresponds to the adsorbed molecular $\mathrm{CO}_{2}$ in graphene oxide resulting from physical $\mathrm{CO}_{2}$ adsorption. They reported that the maximum adsorption capacity was $21.6 \mathrm{mmol} / \mathrm{g}$ at $298 \mathrm{~K}$ and $11 \mathrm{bar}$. This value is higher than that of other adsorbents. In addition, they compared the $\mathrm{CO}_{2}$ adsorption capacity of graphene oxide with those of other usual adsorbents, such as, carbon materials, MOF, zeolite, and so on, as mentioned below.

Before everything else, Mishra and Ramaprabhu [105] reported $\mathrm{CO}_{2}$ adsorption capacity, obtained by study of multiwalled carbon nanotubes, was observed to be 11.7, 8.3, and 7.0 $\mathrm{mmol} / \mathrm{g}$ at $11 \mathrm{bar}$ and $25^{\circ} \mathrm{C}, 50^{\circ} \mathrm{C}$, and $100^{\circ} \mathrm{C}$, respectively. Also, Siriwardane et al. [106] and Gensterblum et al. [107] reported $7 \mathrm{mmol} / \mathrm{g}$ and $6 \mathrm{mmol} / \mathrm{g}$, respectively, of $\mathrm{CO}_{2}$ adsorption in activated carbon at $45^{\circ} \mathrm{C}$ and 11 bar. Zhang et al. [108] reported enhancement of around $20 \%$ in $\mathrm{CO}_{2}$ uptake, which was achieved by modifying the $\mathrm{AC}$ with nitrogen at $298 \mathrm{~K}$, and adsorption capacity was about $16 \mathrm{mmol} / \mathrm{g}$ adsorption capacity at 11 bar. Cavenati et al. [109] reported $3.2 \mathrm{mmol} / \mathrm{g}$ of $\mathrm{CO}_{2}$ adsorption in $13 \mathrm{X}$ zeolite at $298 \mathrm{~K}$ and 12 bar. A high-pressure $\mathrm{CO}_{2}$ adsorption study on various metal organic frameworks by Millward and Yaghi [110] achieved $\mathrm{CO}_{2}$ adsorption capacity ranging from 2 to $8 \mathrm{mmol} / \mathrm{g}$ under similar conditions.

In addition, Wang et al. [94] reported $\mathrm{CO}_{2}$ adsorption by graphene oxide. They studied the $\mathrm{CO}_{2}$ adsorption of graphene oxide at $195 \mathrm{~K}$ and $1 \mathrm{bar}$, which conditions showed somewhat variable values of $\mathrm{CO}_{2}$ uptake in the range from 10 to $38 \mathrm{wt} \%$. It is possible that low $\mathrm{CO}_{2}$ uptake values can occur in graphene samples containing large particulates.

Next, we will discuss metal-loaded graphene composites for $\mathrm{CO}_{2}$ adsorption. As shown in Fig. 20, Cazorla et al. [111] performed a first-principles study of $\mathrm{CO}_{2}$ adsorbent materials consisting of calcium atoms and carbon-based nanostructures.

They found that $\mathrm{Ca}$-decorated graphene possesses unusually large $\mathrm{CO}_{2}$ uptake capacities in the range from 0.1 to 0.4 $\mathrm{g} \mathrm{CO}_{2} / \mathrm{g}$ sorbent under a low-gas-pressure regime as a result of their unique topology and a strong interaction between the metal nanoparticles and $\mathrm{CO}_{2}$ molecules. It is also reported that the strength of the $\mathrm{Ca}$ metal and $\mathrm{CO}_{2}$ molecule interactions can be efficiently tuned as a function of the Ca loading content (Table 3).

Enhancement of the $\mathrm{CO}_{2}$ reactivity properties of carbons in the presence of $\mathrm{Ca}$ atoms can be understood in terms of electronic structure, that is, overlapping of s,d-metallic and p-molecular states in the region near the Fermi level. Thus, by use

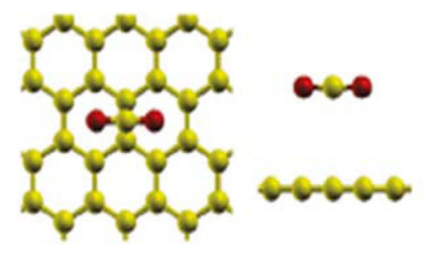

(a)

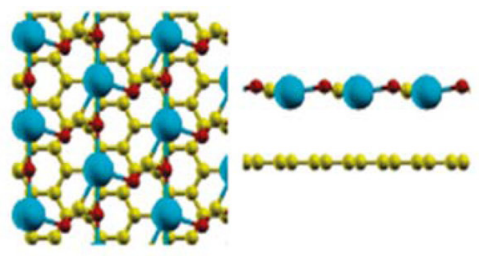

(b)

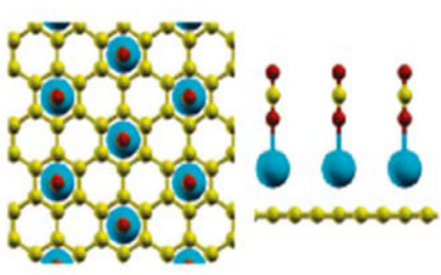

(c)

Fig. 20. Carbon capture geometry optimized structure obtained; (a) pristine graphene, (b) Ca/graphene at $12.5 \%$, and (c) Ca/graphene at $16.67 \%$. 
Table 3. Binding energy (per $\mathrm{CO}_{2}$ molecule) and corresponding gas-adsorption capacities of $\mathrm{Ca} /$ graphene as a function of $\mathrm{Ca}$ content

\begin{tabular}{ccc} 
Ca content $(\%)$ & $\begin{array}{c}\text { Binding energy } \\
(\mathrm{eV} / \text { molecule })\end{array}$ & $\begin{array}{c}\mathrm{CO}_{2} \text { uptake } \\
\left(\mathrm{g} \mathrm{CO}_{2} / \mathrm{g} \text { sorbent }\right)\end{array}$ \\
\hline 0 & -0.035 & 0.153 \\
\hline $0 \sim 5$ & -1.022 & 0.134 \\
\hline $5 \sim 15$ & -2.731 & 0.323 \\
\hline $15 \sim 20$ & -0.101 & 0.392 \\
\hline
\end{tabular}

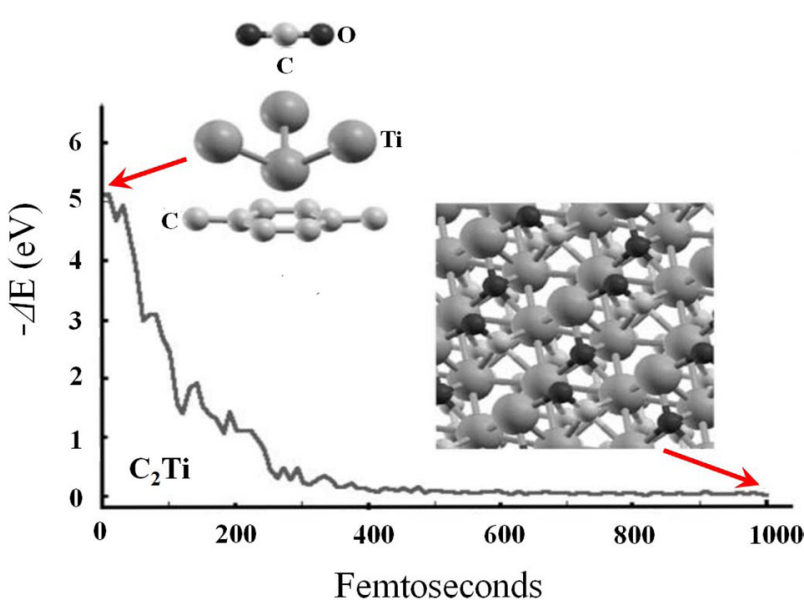

Fig. 21. $\mathrm{CO}_{2}$ adsorption onto Ti-graphene $\left(\mathrm{C}_{2} \mathrm{Ti}\right)$. The final configuration shows the dissociation of the molecule in $\mathrm{CO}$ and $\mathrm{O}$. The initial orientation of the molecule has no influence on the result.

of first-principles simulation techniques, Guo et al. [111] confidently proposed that these $\mathrm{Ca}$ metal/carbon-based nanomaterial composites exhibit characteristics of suitable adsorbents for $\mathrm{CO}_{2}$ capture and sequestration applications.

Carrillo et al. [112] studied the adsorption of $\mathrm{CO}_{2}$ on a Tigraphene system with high metal coverage using the density functional theory and molecular dynamics simulation. Positively charged Ti atoms on graphene surfaces attract negatively charged oxygen atoms towards the graphene surfaces. This force is stronger than the initial repulsion on the $\mathrm{C}$ atom by the $\mathrm{Ti}$ atoms. When a $\mathrm{CO}_{2}$ molecule approaches the graphene surfaces, the $\mathrm{CO}_{2}$ molecule cannot be linear any longer. The $\mathrm{O}$ atoms in a bent $\mathrm{CO}_{2}$ molecule are under different force fields. Thus, one $\mathrm{O}$ atom traps an electronic charge from the Ti atoms of the upper plane and ends bonded to four $\mathrm{Ti}$ atoms, resulting in the $\mathrm{CO}_{2}$ molecule interacting very strongly with the Ti atoms of the upper plane, as can be seen in Fig. 21.

To complete the discussion of Carrillo et al. [112] mentioned above, it is essential to place mono-dispersed Ti atoms on a graphene surface. Ma and Resenberg [113] reported that their experiments showed that adsorbed $\mathrm{Ti}$ atoms on a clean graphite surface tend to form islands or some clusters. Meanwhile, Zhang et al. [114] showed that not only the Ti coating atoms can be dispersed along single-walled carbon nanotubes; $\mathrm{Al}$ and Au nanoparticles are also uniformly deposited on the pre-treated nanotubes, which means that this procedure could facilitate the dispersion of Ti atoms on graphene surfaces.
Table 4. $\mathrm{NH}_{3}$ on graphene: the adsorption energy $\left(E_{a}\right)$ and the charge transfer $(\Delta Q)$ from graphene to the molecule for various adsorption sites and orientations

\begin{tabular}{cccc} 
Position & Orientation & $E_{\mathrm{a}}(\mathrm{meV})$ & $\Delta Q(e)$ \\
\hline $\mathrm{B}$ & $u$ & 21 & -0.026 \\
\hline $\mathrm{T}$ & $u$ & 20 & -0.026 \\
\hline $\mathrm{C}$ & $u$ & 31 & -0.027 \\
\hline $\mathrm{B}$ & $d$ & 15 & -0.001 \\
\hline $\mathrm{T}$ & $d$ & 16 & 0.000 \\
\hline $\mathrm{C}$ & $d$ & 25 & 0.001 \\
\hline
\end{tabular}

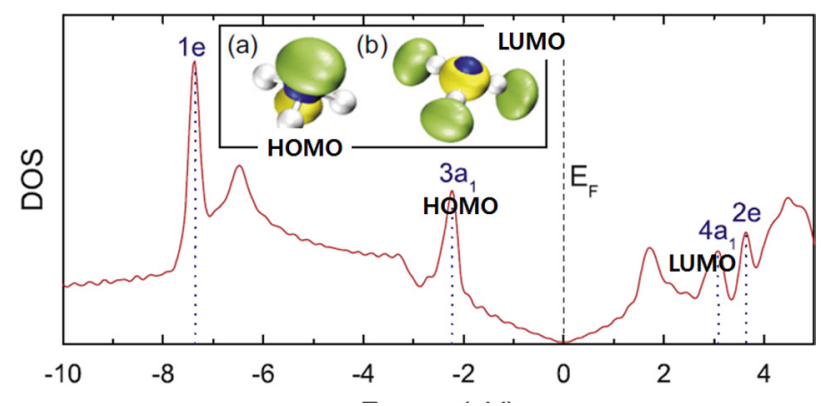

Fig. 22. The density of states (DOS) of graphene with adsorbed $\mathrm{NH}_{3}$ molecule calculated with a $60 \times 60 \times 1 \mathrm{MP}$ grid and a Gaussian smearing of $0.14 \mathrm{eV}$. The dotted vertical lines show the molecular orbitals of $\mathrm{NH}_{3}$.

\subsection{Ammonia adsorption}

Hugo et al. [115] reported studies of the interaction of $\mathrm{NH}_{3}$ with a graphene field-effect transistor (FETs) supported on $\mathrm{Si}$ / $\mathrm{SiO}_{2}$ substrates to provide further insight into the nature of the molecule-graphene interaction mechanism. Here, $\mathrm{SiO}_{2}$ is used as a gate dielectric, and the heavily doped Si substrate is used as the bottom gate electrode. From the study, they elucidated that graphene FETs initially behave as a p-type system due to exposure to air, while these FETs can be rendered n-type by longterm vacuum-degassing at $200^{\circ} \mathrm{C}$.

Leenaerts et al. [116] investigated the adsorption process of $\mathrm{NH}_{3}$ molecules on graphene through first-principle calculations and showed the presence of two main charge transfer mechanisms. They considered two different orientations of $\mathrm{NH}_{3}$ molecules with respect to the graphene surface: (i) the $\mathrm{H}$ atoms pointing away from the surface $(u)$ and (ii) the $\mathrm{H}$ atoms pointing toward the surface $(d)$. They showed the calculated adsorption energies and charge transfers (Table 4). It was found that the charge transfer is only determined by the orientation of the molecule and not by the adsorption sites. There is a small charge transfer of $0.03 e$ from the molecule to the graphene surface in the $u$ orientation; there is almost no charge transfer in the $d$ orientation.

Fig. 22 shows this dependence on the orientation can be understood in terms of the highest occupied and lowest unoccupied molecular orbital (HOMO and LUMO) of the molecule and the total density of states of the system. The HOMO and LUMO are both close enough to the Dirac point to cause some charge trans- 
fer through orbital mixing (hybridization) with the graphene orbital. In the u orientation, the $\mathrm{NH}_{3}$ molecule acts as a donor, because the HOMO is the only orbital that can have a significant overlap with the graphene orbitals, and as a consequence, acts as a donor in this orientation. Meanwhile, in the d orientation, both the HOMO and LUMO of the $\mathrm{NH}_{3}$ molecule are able to interact with graphene. This leads to competing charge transfers to and away from graphene, resulting in a total charge transfer close to zero. As observed experimentally in their study, the u orientation is energetically favored, which explains the donor character of $\mathrm{NH}_{3}$ molecules.

\section{Summary}

The field of graphene-related research has grown at a spectacular pace since a single-layer flake was first isolated in 2004. The Nobel Prize in Physics 2010 was awarded to Andre Geim and Konstantin Novoselov for ground breaking experiments. Graphene and graphene-based materials are promising candidates as components in various applications due to their superior properties. Recently, the development of various methods for producing these materials has stimulated a vast amount of research, for example, epitaxial growth and chemical vapor deposition techniques, micromechanical exfoliation, chemical reduction, and thermal exfoliation, microwave treatments, and conversion of nanodiamonds. A proper understading of the growth and properties of graphene is a must for its optimal utilization.

The main purpose of this review was to comprehensive the synthesis method of graphene and to brief the adsorption behaviors of graphene and graphene-based materials. We have also reported not only the nature of adsorption sites for various gases on their surfaces for high $\mathrm{H}_{2}$ storage capacity and $\mathrm{CO}_{2}$ capture, but the sensor ability for detecting individual gas molecules. The superior adsorption behaviors of graphene and graphene-based materials might be attributable to their large specific surface area and special interaction between electron-donor and acceptor molecules.

\section{Acknowledgements}

We acknowledge the financial support by grants from Korea CCS R\&D Center, funded by the Ministry of Education, Science and Technology of Korean government.

\section{References}

[1] Novoselov KS, Geim AK, Morozov SV, Jiang D, Zhang Y, Dubonos SV, Grigorieva IV, Firsov AA. Electric field effect in atomically thin carbon films. Science, 306, 666 (2004). http://dx.doi. org/10.1126/science.1102896.

[2] Tkachev S, Buslaeva E, Gubin S. Graphene: a novel carbon nanomaterial. Inorg Mater, 47, 1 (2011). http://dx.doi.org/10.1134/ s0020168511010134.

[3] Singh V, Joung D, Zhai L, Das S, Khondaker SI, Seal S. Graphene based materials: past, present and future. Prog Mater Sci, 56, 1178
(2011). http://dx.doi.org/10.1016/j.pmatsci.2011.03.003.

[4] Novoselov KS, Jiang Z, Zhang Y, Morozov SV, Stormer HL, Zeitler U, Maan JC, Boebinger GS, Kim P, Geim AK. Room-temperature quantum Hall effect in graphene. Science, 315, 1379 (2007). http:// dx.doi.org/10.1126/science.1137201.

[5] Ritter KA, Lyding JW. The influence of edge structure on the electronic properties of graphene quantum dots and nanoribbons. Nat Mater, 8, 235 (2009). http://dx.doi.org/10.1038/nmat2378.

[6] Ubbelohde AR, Lewis FA. Graphite and its Crystal Compounds, Clarendon Press, Oxford (1960).

[7] Geim AK, Novoselov KS. The rise of graphene. Nat Mater, 6, 183 (2007). http://dx.doi.org/10.1038/nmat1849.

[8] Chung DDL. Review graphite. J Mater Sci, 37, 1475 (2002). http:// dx.doi.org/10.1023/a:1014915307738.

[9] Stoller MD, Park S, Zhu Y, An J, Ruoff RS. Graphene-based ultracapacitors. Nano Lett, 8, 3498 (2008). http://dx.doi.org/10.1021/ nl802558y.

[10] Bunch JS, van der Zande AM, Verbridge SS, Frank IW, Tanenbaum DM, Parpia JM, Craighead HG, McEuen PL. Electromechanical resonators from graphene sheets. Science, 315, 490 (2007). http:// dx.doi.org/10.1126/science.1136836.

[11] Balandin AA, Ghosh S, Bao W, Calizo I, Teweldebrhan D, Miao F, Lau CN. Superior thermal conductivity of single-layer graphene. Nano Lett, 8, 902 (2008). http://dx.doi.org/10.1021/n10731872.

[12] Li X, Wang X, Zhang L, Lee S, Dai H. Chemically derived, ultrasmooth graphene nanoribbon semiconductors. Science, 319, 1229 (2008). http://dx.doi.org/10.1126/science.1150878.

[13] Shenderova OA, Zhirnov VV, Brenner DW. Carbon nanostructures. Crit Rev Solid State Mater Sci, 27, 227 (2002). http://dx.doi. org/10.1080/10408430208500497.

[14] Krishnan A, Dujardin E, Treacy MMJ, Hugdahl J, Lynum S, Ebbesen TW. Graphitic cones and the nucleation of curved carbon surfaces. Nature, 388, 451 (1997).

[15] Nagashima A, Nuka K, Itoh H, Ichinokawa T, Oshima C, Otani $\mathrm{S}$. Electronic states of monolayer graphite formed on $\mathrm{TiC}(111)$ surface. Surf Sci, 291, 93 (1993). http://dx.doi.org/10.1016/00396028(93)91480-d.

[16] Forbeaux I, Themlin JM, Debever JM. Heteroepitaxial graphite on $6 \mathrm{H}-\mathrm{SiC}(0001)$ : interface formation through conduction-band electronic structure. Phys Rev B, 58, 16396 (1998). http://dx.doi. org/10.1103/PhysRevB.58.16396.

[17] Wu J, Becerril HA, Bao Z, Liu Z, Chen Y, Peumans P. Organic solar cells with solution-processed graphene transparent electrodes. Appl Phys Lett, 92, 263302 (2008). http://dx.doi. org/10.1063/1.2924771.

[18] Ohta T, Bostwick A, Seyller T, Horn K, Rotenberg E. Controlling the electronic structure of bilayer graphene. Science, 313, 951 (2006). http://dx.doi.org/10.1126/science.1130681.

[19] de Heer WA, Berger C, Wu X, First PN, Conrad EH, Li X, Li T, Sprinkle M, Hass J, Sadowski ML, Potemski M, Martinez G. Epitaxial graphene. Solid State Commun, 143, 92 (2007). http:// dx.doi.org/10.1016/j.ssc.2007.04.023.

[20] Emtsev KV, Bostwick A, Horn K, Jobst J, Kellogg GL, Ley L, McChesney JL, Ohta T, Reshanov SA, Rohrl J, Rotenberg E, Schmid AK, Waldmann D, Weber HB, Seyller T. Towards wafersize graphene layers by atmospheric pressure graphitization of silicon carbide. Nat Mater, 8, 203 (2009). http://dx.doi.org/10.1038/ nmat2382.

[21] Kim KS, Zhao Y, Jang H, Lee SY, Kim JM, Kim KS, Ahn JH, Kim 
P, Choi JY, Hong BH. Large-scale pattern growth of graphene films for stretchable transparent electrodes. Nature, 457, 706 (2009). http://dx.doi.org/10.1038/nature07719.

[22] Reina A, Jia X, Ho J, Nezich D, Son H, Bulovic V, Dresselhaus MS, Kong J. Large area, few-layer graphene films on arbitrary substrates by chemical vapor deposition. Nano Lett, 9, 30 (2008). http://dx.doi.org/10.1021/n1801827v.

[23] Yu Q, Lian J, Siriponglert S, Li H, Chen YP, Pei S-S. Graphene segregated on Ni surfaces and transferred to insulators. Appl Phys Lett, 93, 113103 (2008). http://dx.doi.org/10.1063/1.2982585.

[24] Li X, Cai W, An J, Kim S, Nah J, Yang D, Piner R, Velamakanni A, Jung I, Tutuc E, Banerjee SK, Colombo L, Ruoff RS. Large-area synthesis of high-quality and uniform graphene films on copper foils. Science, 324, 1312 (2009). http://dx.doi.org/10.1126/science. 1171245 .

[25] Berger C, Song Z, Li X, Wu X, Brown N, Naud C, Mayou D, Li T, Hass J, Marchenkov AN, Conrad EH, First PN, de Heer WA. Electronic confinement and coherence in patterned epitaxial graphene. Science, 312, 1191 (2006). http://dx.doi.org/10.1126/science. 1125925 .

[26] Hass J, Heer WAd, Conrad EH. The growth and morphology of epitaxial multilayer graphene. J Phys: Condens Matter, 20, 323202 (2008). http://dx.doi.org/10.1088/0953-8984/20/32/323202.

[27] Bae S, Kim H, Lee Y, Xu X, Park JS, Zheng Y, Balakrishnan J, Lei T, Ri Kim H, Song YI, Kim YJ, Kim KS, Ozyilmaz B, Ahn JH, Hong BH, Iijima S. Roll-to-roll production of 30-inch graphene films for transparent electrodes. Nat Nanotechnol, 5, 574 (2010). http://dx.doi.org/10.1038/nnano.2010.132.

[28] Berger C, Song Z, Li T, Li X, Ogbazghi AY, Feng R, Dai Z, Marchenkov AN, Conrad EH, First PN, de Heer WA. Ultrathin epitaxial graphite: $2 \mathrm{D}$ electron gas properties and a route toward graphenebased nanoelectronics. J Phys Chem B, 108, 19912 (2004). http:// dx.doi.org/10.1021/jp040650f.

[29] Jauregui LA, Cao H, Wu W, Yu Q, Chen YP. Electronic properties of grains and grain boundaries in graphene grown by chemical vapor deposition. Solid State Commun, 151, 1100 (2011). http:// dx.doi.org/10.1016/j.ssc.2011.05.023.

[30] Cao H, Yu Q, Jauregui LA, Tian J, Wu W, Liu Z, Jalilian R, Benjamin DK, Jiang Z, Bao J, Pei SS, Chen YP. Electronic transport in chemical vapor deposited graphene synthesized on $\mathrm{Cu}$ : quantum Hall effect and weak localization. Appl Phys Lett, 96, 122106 (2010). http://dx.doi.org/10.1063/1.3371684.

[31] Eizenberg M, Blakely JM. Carbon monolayer phase condensation on Ni(111). Surf Sci, 82, 228 (1979). http://dx.doi. org/10.1016/0039-6028(79)90330-3.

[32] Isett LC, Blakely JM. Segregation isosteres for carbon at the (100) surface of nickel. Surf Sci, 58, 397 (1976). http://dx.doi. org/10.1016/0039-6028(76)90478-7.

[33] Somani PR, Somani SP, Umeno M. Planer nano-graphenes from camphor by CVD. Chem Phys Lett, 430, 56 (2006). http://dx.doi. org/10.1016/j.cplett.2006.06.081.

[34] Chen YP, Yu Q. Nanomaterials: graphene rolls off the press. Nat Nanotechnol, 5, 559 (2010). http://dx.doi.org/10.1038/nnano.2010.158.

[35] Meyer JC, Geim AK, Katsnelson MI, Novoselov KS, Booth TJ, Roth $\mathrm{S}$. The structure of suspended graphene sheets. Nature, 446, 60 (2007). http://dx.doi.org/10.1038/nature05545.

[36] Bolotin KI, Sikes KJ, Jiang Z, Klima M, Fudenberg G, Hone J, Kim P, Stormer HL. Ultrahigh electron mobility in suspended graphene. Solid State Commun, 146, 351 (2008). http://dx.doi. org/10.1016/j.ssc.2008.02.024.

[37] Bolotin KI, Sikes KJ, Hone J, Stormer HL, Kim P. Temperature-dependent transport in suspended graphene. Phys Rev Lett, 101, 096802 (2008). http://dx.doi.org/10.1103/PhysRevLett.101.096802.

[38] Novoselov KS, Jiang D, Schedin F, Booth TJ, Khotkevich VV, Morozov SV, Geim AK. Two-dimensional atomic crystals. Proc Natl Acad Sci USA, 102, 10451 (2005). http://dx.doi.org/10.1073/ pnas.0502848102.

[39] Park SJ. van der Waals interaction at surfaces. In: Somasundaran P, ed. Encyclopedia of Surface and Colloid Science. 2nd ed., Taylor \& Francis, New York, 5570 (2006).

[40] Park SJ. Long-range force contributions to surface dynamics. In: Hsu JP, ed. Interfacial Forces and Fields: Theory and Applications, Marcel Dekker, New York, 385 (1999).

[41] Li X, Cai W, Colombo L, Ruoff RS. Evolution of graphene growth on $\mathrm{Ni}$ and $\mathrm{Cu}$ by carbon isotope labeling. Nano Lett, 9, 4268 (2009). http://dx.doi.org/10.1021/n1902515k.

[42] Park SJ, Seo MK. Interface Science and Composites, Academic Press, Boston (2011).

[43] Hummers WS Jr, Offeman RE. Preparation of graphitic oxide. J Am Chem Soc, 80, 1339 (1958). http://dx.doi.org/10.1021/ ja01539a017.

[44] Allen MJ, Tung VC, Kaner RB. Honeycomb carbon: a review of graphene. Chem Rev, 110, 132 (2009). http://dx.doi.org/10.1021/ cr900070d.

[45] Hernandez Y, Nicolosi V, Lotya M, Blighe FM, Sun Z, De S, McGovern IT, Holland B, Byrne M, Gun'Ko YK, Boland JJ, Niraj P, Duesberg G, Krishnamurthy S, Goodhue R, Hutchison J, Scardaci V, Ferrari AC, Coleman JN. High-yield production of graphene by liquid-phase exfoliation of graphite. Nat Nanotechnol, 3, 563 (2008). http://dx.doi.org/10.1038/nnano.2008.215.

[46] Lotya M, Hernandez Y, King PJ, Smith RJ, Nicolosi V, Karlsson LS, Blighe FM, De S, Wang Z, McGovern IT, Duesberg GS, Coleman JN. Liquid phase production of graphene by exfoliation of graphite in surfactant/water solutions. J Am Chem Soc, 131, 3611 (2009). http://dx.doi.org/10.1021/ja807449u.

[47] Marcano DC, Kosynkin DV, Berlin JM, Sinitskii A, Sun Z, Slesarev A, Alemany LB, Lu W, Tour JM. Improved synthesis of graphene oxide. ACS Nano, 4, 4806 (2010). http://dx.doi.org/10.1021/ nn1006368.

[48] Kim KS, Park SJ. Influence of multi-walled carbon nanotubes on the electrochemical performance of graphene nanocomposites for supercapacitor electrodes. Electrochim Acta, 56, 1629 (2011). http://dx.doi.org/10.1016/j.electacta.2010.10.043.

[49] Nakajima T, Mabuchi A, Hagiwara R. A new structure model of graphite oxide. Carbon, 26, 357 (1988). http://dx.doi. org/10.1016/0008-6223(88)90227-8.

[50] Stankovich S, Dikin DA, Piner RD, Kohlhaas KA, Kleinhammes A, Jia Y, Wu Y, Nguyen ST, Ruoff RS. Synthesis of graphenebased nanosheets via chemical reduction of exfoliated graphite oxide. Carbon, 45, 1558 (2007). http://dx.doi.org/10.1016/j.carbon.2007.02.034.

[51] Lomeda JR, Doyle CD, Kosynkin DV, Hwang WF, Tour JM. Diazonium functionalization of surfactant-wrapped chemically converted graphene sheets. J Am Chem Soc, 130, 16201 (2008). http:// dx.doi.org/10.1021/ja806499w.

[52] Tung VC, Allen MJ, Yang Y, Kaner RB. High-throughput solution 
processing of large-scale graphene. Nat Nanotechnol, 4, 25 (2009). http://dx.doi.org/10.1038/nnano.2008.329.

[53] Ren PG, Yan DX, Ji X, Chen T, Li ZM. Temperature dependence of graphene oxide reduced by hydrazine hydrate. Nanotechnology, 22, 055705 (2011). http://dx.doi.org/10.1088/09574484/22/5/055705.

[54] Stankovich S, Dikin DA, Dommett GHB, Kohlhaas KM, Zimney EJ, Stach EA, Piner RD, Nguyen ST, Ruoff RS. Graphenebased composite materials. Nature, 442, 282 (2006). http://dx.doi. org/10.1038/nature04969.

[55] Wang G, Yang J, Park J, Gou X, Wang B, Liu H, Yao J. Facile synthesis and characterization of graphene nanosheets. J Phys Chem C, 112, 8192 (2008). http://dx.doi.org/10.1021/jp710931h.

[56] Si Y, Samulski ET. Synthesis of water soluble graphene. Nano Lett, 8, 1679 (2008). http://dx.doi.org/10.1021/n1080604h.

[57] Erickson K, Erni R, Lee Z, Alem N, Gannett W, Zettl A. Determination of the local chemical structure of graphene oxide and reduced graphene oxide. Adv Mater, 22, 4467 (2010). http://dx.doi. org/10.1002/adma.201000732.

[58] McAllister MJ, Li JL, Adamson DH, Schniepp HC, Abdala AA, Liu J, Herrera-Alonso M, Milius DL, Car R, Prud'homme RK, Aksay IA. Single sheet functionalized graphene by oxidation and thermal expansion of graphite. Chem Mater, 19, 4396 (2007). http:// dx.doi.org/10.1021/cm0630800.

[59] Schniepp HC, Li J-L, McAllister MJ, Sai H, Herrera-Alonso M, Adamson DH, Prud'homme RK, Car R, Saville DA, Aksay IA. Functionalized single graphene sheets derived from splitting graphite oxide. J Phys Chem B, 110, 8535 (2006). http://dx.doi. org/10.1021/jp060936f.

[60] Kaniyoor A, Baby TT, Arockiadoss T, Rajalakshmi N, Ramaprabhu S. Wrinkled graphenes: a study on the effects of synthesis parameters on exfoliation-reduction of graphite oxide. J Phys Chem C, 115, 17660 (2011). http://dx.doi.org/10.1021/jp204039k.

[61] Subrahmanyam KS, Vivekchand SRC, Govindaraj A, Rao CNR. A study of graphenes prepared by different methods: characterization, properties and solubilization. J Mater Chem, 18, 1517 (2008). http://dx.doi.org/10.1039/B716536F.

[62] Rao CNR, Sood AK, Subrahmanyam KS, Govindaraj A. Graphene: the new two-dimensional nanomaterial. Angew Chem Int Ed, 48, 7752 (2009). http://dx.doi.org/10.1002/anie.200901678.

[63] Morales GM, Schifani P, Ellis G, Ballesteros C, Martínez G, Barbero C, Salavagione HJ. High-quality few layer graphene produced by electrochemical intercalation and microwave-assisted expansion of graphite. Carbon, 49, 2809 (2011). http://dx.doi. org/10.1016/j.carbon.2011.03.008.

[64] Andersson OE, Prasad BLV, Sato H, Enoki T, Hishiyama Y, Kaburagi Y, Yoshikawa M, Bandow S. Structure and electronic properties of graphite nanoparticles. Phys Rev B, 58, 16387 (1998). http://dx.doi.org/10.1103/PhysRevB.58.16387.

[65] Prasad BLV, Sato H, Enoki T, Hishiyama Y, Kaburagi Y, Rao AM, Eklund PC, Oshida K, Endo M. Heat-treatment effect on the nanosized graphite $\pi$-electron system during diamond to graphite conversion. Phys Rev B, 62, 11209 (2000). http://dx.doi.org/10.1103/ PhysRevB.62.11209.

[66] Subrahmanyam KS, Panchakarla LS, Govindaraj A, Rao CNR. Simple method of preparing graphene flakes by an arc-discharge method. J Phys Chem C, 113, 4257 (2009). http://dx.doi. org/10.1021/jp900791y.

[67] Rao CNR, Subrahmanyam KS, Matte HSSR, Abdulhakeem B, Go- vindaraj A, Barun D, Prashant K, Anupama G, Dattatray JL. A study of the synthetic methods and properties of graphenes. Sci Technol Adv Mater, 11, 054502 (2010). http://dx.doi.org/10.1088/14686996/11/5/054502.

[68] Seshadri R, Govindaraj A, Aiyer HN, Sen R, Subbanna GN, Raju AR, Rao CNR. Investigations of carbon nanotubes. Curr Sci, 66, 839 (1994).

[69] Zhang RQ, Sarkar AD. Theoretical studies on formation, property, tuning and adsorption of graphene segments. In: Mikhailov S, ed. Physics and Applications of Graphene--Theory, InTech Openbook, Chapter 1 (2011).

[70] Lin CS, Zhang RQ, Lee ST, Elstner M, Frauenheim T, Wan LJ. Simulation of water cluster assembly on a graphite surface. J Phys Chem B, 109, 14183 (2005). http://dx.doi.org/10.1021/jp0504591.

[71] Kim BJ, Lee YS, Park SJ. Novel porous carbons synthesized from polymeric precursors for hydrogen storage. Int J Hydrogen Energy, 33, 2254 (2008). http://dx.doi.org/10.1016/j.ijhydene.2008. 02.019 .

[72] Yoo HM, Lee SY, Kim BJ, Park SJ. Influence of phosphoric acid treatment on hydrogen adsorption behaviors of activated carbons. Carbon Lett, 12, 112 (2011). http://dx.doi.org/10.5714/ CL.2011.12.2.112.

[73] Saha D, Deng S. Hydrogen adsorption on Pd- and Ru-doped C60 fullerene at an ambient temperature. Langmuir, 27, 6780 (2011). http://dx.doi.org/10.1021/la200091s.

[74] Chen J, Wu F. Review of hydrogen storage in inorganic fullerene-like nanotubes. Appl Phys A, 78, 989 (2004). http://dx.doi. org/10.1007/s00339-003-2419-7.

[75] Lee SY, Park SJ. Effect of temperature on activated carbon nanotubes for hydrogen storage behaviors. Int J Hydrogen Energy, 35, 6757 (2010). http://dx.doi.org/10.1016/j.ijhydene.2010.03.114.

[76] Park SJ, Lee SY. Hydrogen storage behaviors of platinum-supported multi-walled carbon nanotubes. Int J Hydrogen Energy, 35, 13048 (2010). http://dx.doi.org/10.1016/j.ijhydene.2010.04.083.

[77] Lee SY, Park SJ. Influence of $\mathrm{CO}_{2}$ activation on hydrogen storage behaviors of platinum-loaded activated carbon nanotubes. J Solid State Chem, 183, 2951 (2010). http://dx.doi.org/10.1016/j. jssc.2010.08.035.

[78] Lee SY, Park SJ. Effect of chemical treatments on hydrogen storage behaviors of multi-walled carbon nanotubes. Mater Chem Phys, 124, 1011 (2010). http://dx.doi.org/10.1016/j.matchemphys.2010.08.022.

[79] Jung MJ, Im JS, Jeong E, Jin H, Lee YS. Hydrogen adsorption of pan-based porous carbon nanofibers using $\mathrm{MgO}$ as the substrate. Carbon Lett, 10, 217 (2009).

[80] Sharon M, Sharon M, Kalita G, Mukherjee B. Hydrogen storage by carbon fibers synthesized by pyrolysis of cotton fibers. Carbon Lett, 12, 39 (2011).

[81] Im JS, Kwon O, Kim YH, Park SJ, Lee YS. The effect of embedded vanadium catalyst on activated electrospun CFs for hydrogen storage. Microporous Mesoporous Mater, 115, 514 (2008). http:// dx.doi.org/10.1016/j.micromeso.2008.02.027.

[82] Lee SY, Park SJ. Preparation and characterization of ordered porous carbons for increasing hydrogen storage behaviors. J Solid State Chem, 184, 2655 (2011). http://dx.doi.org/10.1016/j. jssc.2011.07.034.

[83] Jiang J, Gao Q, Zheng Z, Xia K, Hu J. Enhanced room temperature hydrogen storage capacity of hollow nitrogen-containing carbon spheres. Int J Hydrogen Energy, 35, 210 (2010). http://dx.doi. 
org/10.1016/j.ijhydene.2009.10.042.

[84] Lee SY, Park SJ. Effect of platinum doping of activated carbon on hydrogen storage behaviors of metal-organic frameworks-5. Int J Hydrogen Energy, 36, 8381 (2011). http://dx.doi.org/10.1016/j. ijhydene.2011.03.038.

[85] Park SJ, Lee SY. Hydrogen storage behaviors of carbon nanotubes/ metal-organic frameworks-5. Carbon Lett, 10, 19 (2009).

[86] Tylianakis E, Psofogiannakis GM, Froudakis GE. Li-doped pillared graphene oxide: a graphene-based nanostructured material for hydrogen storage. J Phys Chem Lett, 1, 2459 (2010). http:// dx.doi.org/10.1021/jz100733z.

[87] Srinivas G, Zhu Y, Piner R, Skipper N, Ellerby M, Ruoff R. Synthesis of graphene-like nanosheets and their hydrogen adsorption capacity. Carbon, 48, 630 (2010). http://dx.doi.org/10.1016/j.carbon.2009.10.003.

[88] Bourlinos AB, Steriotis TA, Karakassides M, Sanakis Y, Tzitzios V, Trapalis C, Kouvelos E, Stubos A. Synthesis, characterization and gas sorption properties of a molecularly-derived graphite oxidelike foam. Carbon, 45, 852 (2007). http://dx.doi.org/10.1016/j.carbon.2006.11.008.

[89] Ma LP, Wu ZS, Li J, Wu ED, Ren WC, Cheng HM. Hydrogen adsorption behavior of graphene above critical temperature. Int $\mathrm{J}$ Hydrogen Energy, 34, 2329 (2009). http://dx.doi.org/10.1016/j. ijhydene.2008.12.079

[90] Ghosh A, Subrahmanyam KS, Krishna KS, Datta S, Govindaraj A, Pati SK, Rao CNR. Uptake of $\mathrm{H}_{2}$ and $\mathrm{CO}_{2}$ by graphene. J Phys Chem C, 112, 15704 (2008). http://dx.doi.org/10.1021/ jp805802w.

[91] Peigney A, Laurent C, Flahaut E, Bacsa RR, Rousset A. Specific surface area of carbon nanotubes and bundles of carbon nanotubes. Carbon, 39, 507 (2001). http://dx.doi.org/10.1016/s00086223(00)00155-x.

[92] Kaneko K, Ishii C, Ruike M, kuwabara H. Origin of superhigh surface area and microcrystalline graphitic structures of activated carbons. Carbon, 30, 1075 (1992). http://dx.doi.org/10.1016/00086223(92)90139-n.

[93] Bhatia SK, Myers AL. Optimum conditions for adsorptive storage. Langmuir, 22, 1688 (2006). http://dx.doi.org/10.1021/la0523816.

[94] Wang L, Lee K, Sun YY, Lucking M, Chen Z, Zhao JJ, Zhang SB. Graphene oxide as an ideal substrate for hydrogen storage. ACS Nano, 3, 2995 (2009). http://dx.doi.org/10.1021/nn900667s.

[95] Kim BJ, Park SJ. Optimization of the pore structure of nickel/ graphite hybrid materials for hydrogen storage. Int $\mathrm{J}$ Hydrogen Energy, 36, 648 (2011). http://dx.doi.org/10.1016/j. ijhydene.2010.09.097.

[96] Kubas GJ, Ryan RR, Swanson BI, Vergamini PJ, Wasserman HJ. Characterization of the first examples of isolable molecular hydrogen complexes, $\mathrm{M}(\mathrm{CO})_{3}\left(\mathrm{PR}_{3}\right)_{2}\left(\mathrm{H}_{2}\right)(\mathrm{M}=$ molybdenum or tungsten; $\mathrm{R}=\mathrm{Cy}$ or isopropyl). Evidence for a side-on bonded dihydrogen ligand. J Am Chem Soc, 106, 451 (1984). http://dx.doi.org/10.1021/ ja00314a049.

[97] Kubas GJ. Molecular hydrogen complexes: coordination of a .sigma. bond to transition metals. Acc Chem Res, 21, 120 (1988). http://dx.doi.org/10.1021/ar00147a005.

[98] Hoang TKA, Antonelli DM. Exploiting the Kubas interaction in the design of hydrogen storage materials. Adv Mater, 21, 1787 (2009). http://dx.doi.org/10.1002/adma.200802832.

[99] Singh AK, Sadrzadeh A, Yakobson BI. Metallacarboranes: toward promising hydrogen storage metal organic frameworks. J
Am Chem Soc, 132, 14126 (2010). http://dx.doi.org/10.1021/ ja104544s.

[100] Skipper CVJ, Hamaed A, Antonelli DM, Kaltsoyannis N. Computational study of silica-supported transition metal fragments for Kubas-type hydrogen storage. J Am Chem Soc, 132, 17296 (2010). http://dx.doi.org/10.1021/ja107539j.

[101] Hamaed A, Hoang TKA, Moula G, Aroca R, Trudeau ML, Antonelli DM. Hydride-induced amplification of performance and binding enthalpies in chromium hydrazide gels for Kubas-type hydrogen storage. J Am Chem Soc, 133, 15434 (2011). http:// dx.doi.org/10.1021/ja2021944.

[102] Zhu H, Chen Y, Li S, Yang X, Liu Y. Novel sandwich-type dimetallocenes: toward promising candidate media for highcapacity hydrogen storage. Int J Hydrogen Energy, 36, 11810 (2011). http://dx.doi.org/10.1016/j.ijhydene.2011.04.024.

[103] Mishra AK, Ramaprabhu S. Carbon dioxide adsorption in graphene sheets. AIP Advances, 1, 032152 (2011). http://dx.doi. org/10.1063/1.3638178.

[104] Kaniyoor A, Baby TT, Ramaprabhu S. Graphene synthesis via hydrogen induced low temperature exfoliation of graphite oxide. J Mater Chem, 20, 8467 (2010). http://dx.doi.org/10.1039/ C0JM01876G.

[105] Mishra AK, Ramaprabhu S. Nano magnetite decorated multiwalled carbon nanotubes: a robust nanomaterial for enhanced carbon dioxide adsorption. Energy Environ Sci, 4, 889 (2011). http://dx.doi.org/10.1039/C0EE00076K.

[106] Siriwardane RV, Shen MS, Fisher EP, Poston JA. Adsorption of $\mathrm{CO}_{2}$ on molecular sieves and activated carbon. Energy Fuels, 15, 279 (2001). http://dx.doi.org/10.1021/ef000241s.

[107] Gensterblum Y, van Hemert P, Billemont P, Busch A, Charriere D, Li D, Krooss BM, de Weireld G, Prinz D, Wolf KHAA. European inter-laboratory comparison of high pressure $\mathrm{CO}_{2}$ sorption isotherms. I: activated carbon. Carbon, 47, 2958 (2009). http:// dx.doi.org/10.1016/j.carbon.2009.06.046.

[108] Zhang Z, Xu M, Wang H, Li Z. Enhancement of $\mathrm{CO}_{2}$ adsorption on high surface area activated carbon modified by $\mathrm{N}_{2}, \mathrm{H}_{2}$ and ammonia. Chem Eng J, 160, 571 (2010). http://dx.doi.org/10.1016/j. cej.2010.03.070.

[109] Cavenati S, Grande CA, Rodrigues AE. Adsorption equilibrium of methane, carbon dioxide, and nitrogen on zeolite $13 \mathrm{X}$ at high pressures. J Chem Eng Data, 49, 1095 (2004). http://dx.doi. org/10.1021/je0498917.

[110] Millward AR, Yaghi OM. Metal-organic frameworks with exceptionally high capacity for storage of carbon dioxide at room temperature. J Am Chem Soc, 127, 17998 (2005). http://dx.doi. org/10.1021/ja0570032.

[111] Cazorla C, Shevlin SA, Guo ZX. Calcium-based functionalization of carbon materials for $\mathrm{CO}_{2}$ capture: a first-principles computational study. J Phys Chem C, 115, 10990 (2011). http:// dx.doi.org/10.1021/jp201786h.

[112] Carrillo I, Rangel E, Magana LF. Adsorption of carbon dioxide and methane on graphene with a high titanium coverage. Carbon, 47, 2758 (2009). http://dx.doi.org/10.1016/j.carbon.2009.06.022.

[113] Ma Q, Rosenberg RA. Interaction of Ti with the (0001) surface of highly oriented pyrolitic graphite. Phys Rev B, 60, 2827 (1999). http://dx.doi.org/10.1103/PhysRevB.60.2827.

[114] Zhang Y, Franklin NW, Chen RJ, Dai H. Metal coating on suspended carbon nanotubes and its implication to metal-tube interaction. Chem Phys Lett, 331, 35 (2000). http://dx.doi. 
org/10.1016/s0009-2614(00)01162-3.

[115] Hugo ER, Prasoon J, Awnish KG, Humberto RG, Milton WC, Srinivas AT, Peter CE. Adsorption of ammonia on graphene. Nanotechnology, 20, 245501 (2009). http://dx.doi.org/10.1088/0957-
$4484 / 20 / 24 / 245501$.

[116] Leenaerts O, Partoens B, Peeters FM. Adsorption of small molecules on graphene. Microelectron J, 40, 860 (2009). http://dx.doi. org/10.1016/j.mejo.2008.11.022. 